\title{
Overall similarity and the identification of separable-dimension stimuli: A choice model analysis
}

\author{
ROBERT NOSOFSKY \\ Indiana University, Bloomington, Indiana
}

\begin{abstract}
Two subjects identified a set of perceptually confusable stimuli varying along two continuous, separable dimensions. The data were analyzed using various restricted versions of the similarity choice model (Luce, 1963; Shepard, 1957). In the main version, the multidimensional scaling approach to modeling similarity was applied and yielded excellent quantitative accounts of the identification data. A surprising result was that the Euclidean metric provided a far better description of psychological distance relationships than the city-block metric, a finding that contrasts with virtually all previous conclusions regarding the appropriate Minkowski r-metric for separabledimension stimuli. Possible reasons for the discrepancy between the present findings and previous conclusions are considered in the General Discussion section, with Shepard's (1964) seminal study examined in depth. In an initial theoretical section, it is also shown that, for factorial stimulus sets, a choice model in which subjects identify values along each component dimension independently is a special case of the full choice model in which overall similarity relationships among stimulus wholes determine identification performance.
\end{abstract}

Among the most fundamental cognitive activities is the process of identifying objects in the environment. Researchers study this process in the laboratory by running identification paradigms in which there is some wellspecified set of stimulus alternatives, with each alternative assigned a unique response. The data obtained in an identification paradigm are summarized in a stimulusresponse confusion matrix, in which cell $(i, j)$ of the matrix gives the frequency with which stimulus $i$ was identified as stimulus $j$. The errors that subjects make in identifying stimuli generally exhibit a high degree of regularity and structure, with stimuli that are similar to one another being confused more often than those that are dissimilar.

The present study is concerned with the identification of stimuli that vary along continuous, separable dimensions. Separable dimensions remain psychologically distinct when in combination, yielding highly analyzable stimuli. By contrast, integral dimensions combine into relatively unanalyzable, unitary wholes. Various converg-

\footnotetext{
This article is based on portions of the $\mathrm{PhD}$ dissertation submitted by this author to Harvard University and on subsequent work conducted at Indiana University. The work was supported by Grants BNS 80-26656 from the National Science Foundation and MH 37208 from the National Institute of Mental Health to Harvard University, and by BRSG Grant S07 RR07031 from the Biomedical Research Support Grant Program at Indiana University. The author was also supported by an Indiana University Summer Faculty Fellowship.

The author's thanks are extended to William K. Estes and R. Duncan Luce, for valuable suggestions, criticisms, and discussions regarding this research, and also to J. E. Keith Smith, for his comments on an earlier version of this article, and to Linda B. Smith, for helpful discussions and advice. The author's mailing address is: Psychology Department, Indiana University, Bloomington, IN 47405.
}

ing operations are used to distinguish between integral and separable dimensions (Garner, 1974). One such operation is that integral and separable dimensions seem to give rise to different similarity structures. There is an extensive literature supporting the idea that although the Euclidean metric may be appropriate for describing psychological distance relationships among integral-dimension stimuli, something more along the lines of the city-block metric is appropriate for separable-dimension stimuli (e.g., Attneave, 1950; Dunn, 1983; Garner, 1974; Handel \& Imai, 1972; Hyman \& Well, 1967, 1968; Shepard, 1964, 1984; Torgerson, 1958; Tversky \& Gati, 1982; Wiener-Ehrlich, 1978).

Most conclusions regarding the appropriate distance metric have been based on studies using judgments of similarity. ${ }^{1}$ Although these judgments are regarded as "direct" measures, the meaningfulness of defining similarity in terms of open-ended, subjective judgments can be questioned. As noted by various researchers (e.g., Krumhansl, 1978; Nosofsky, in press; Torgerson, 1965), complex attention and decision processes are probably involved in similarity-judgment tasks and may obscure the underlying similarity representation. The present research takes a different approach to studying the nature of separable-dimension interactions in determining similarity. Subjects are required simply to identify a set of perceptually confusable, separable-dimension stimuli. We then examine the structure of the interstimulus confusion errors to draw inferences about the underlying similarity representation.

The theoretical analyses of the identification confusion data are organized around the framework provided by the 
similarity choice model (Luce, 1963; Shepard, 1957). According to this model, the probability that stimulus $i$ is identified as stimulus $j, P\left(R_{j} \mid S_{i}\right)$, is given by

$$
\mathbf{P}\left(\mathbf{R}_{\mathbf{j}} \mid \mathbf{S}_{\mathbf{i}}\right)=\frac{\mathbf{b}_{\mathbf{j}} \eta_{\mathbf{i j}}}{\sum_{\mathbf{k}} \mathrm{b}_{\mathbf{k}} \eta_{\mathrm{ik}}},
$$

where $0 \leq b_{j} \leq 1, \Sigma b_{j}=1, \eta_{i j}=\eta_{j i}$, and $\eta_{i i}=1$. The $b_{j}$ parameters are interpreted as response bias parameters and the $\eta_{\mathrm{ij}}$ parameters as similarity measures on stimuli $S_{i}$ and $S_{j}$.

Researchers have had a great deal of success in fitting the choice model to identification confusion data (e.g., Smith, 1980; Townsend, 1971; Townsend \& Ashby, 1982; Townsend \& Landon, 1982). This success comes despite various studies that seem to demonstrate problems with the model's underlying assumptions about stimulus similarity. In his well-known paper "Features of Similarity," for example, Tversky (1977) provided evidence that similarity may not be a symmetric relation (violating the choice model assumption $\eta_{\mathrm{ij}}=\eta_{\mathrm{ji}}$ ) and also suggested that all stimuli may not be equally similar to themselves (violating the assumption $\eta_{\mathrm{ii}}=1$ ). That the choice model has been so successful suggests either that these effects are generally minor or infrequent, or, as suggested by Smith (1980, p. 132), that they may have more to do with the linguistic habits of subjects engaged in similarity-judgment tasks than with the intrinsic properties of stimulus similarity.

The entries in the cells of identification confusion matrices are often interpreted as measures of similarity. Furthermore, it is usually the case that not all entries in the diagonal cells are equal [i.e., $P\left(R_{i} \mid S_{i}\right) \neq P\left(R_{j} \mid S_{j}\right)$ ] and also that confusion errors are not symmetric [i.e., $P\left(R_{j} \mid S_{i}\right)$ $\left.\neq P\left(R_{i} \mid S_{j}\right)\right]$. It should be noted that both occurrences are natural consequences of the choice model decision rule, and that neither has any necessary bearing on the adequacy of the model's assumptions about stimulus similarity. Moreover, this is true even if one is dealing with a bias-free experiment (which is not to say that differential response bias will not also influence the pattern of confusions). Consider the diagram in Figure 1, based on an example provided by Getty, Swets, Swets, and Green (1979, pp. 3-4). Even though stimuli $i$ and $j$ are equally similar to themselves, the bias-free choice model predicts that $j$ will be identified correctly more often than $i$ because $i$ is more similar than $\mathrm{j}$ to the remaining members of the

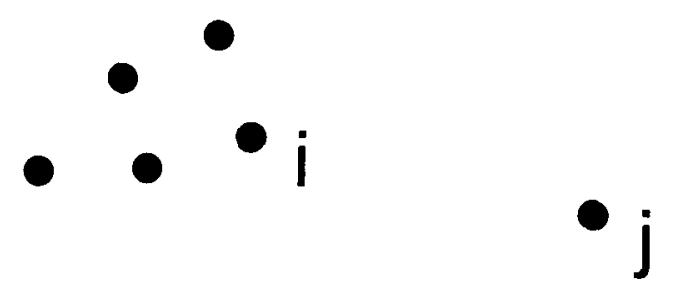

Figure 1. Schematic illustration of a stimulus configuration that would result in asymmetric identification confusion errors and unequal entries along the diagonal cells of the confusion matrix (see text). stimulus set. For the same reason, there would be a greater probability of identifying stimulus $j$ as stimulus $i$ than the reverse. ${ }^{2}$ Krumhansl (1978) developed a distance-density model to account for these types of phenomena. Whereas Krumhansl's model explains violations of symmetry and the like in terms of the underlying similarity representation, the above example suggests that such phenomena may be straightforward outcomes of a simple decision process.

The success of the similarity choice model also stands in contrast to the well-known shortcomings of Luce's (1959) choice axiom (Luce, 1977; Tversky, 1972). Although closely related, the choice model and Luce's (1959) choice axiom are conceptually distinct. The choice model is used to predict the data in a single confusion matrix obtained in a given identification paradigm. By contrast, the choice axiom is an across-matrix predictor used for relating choice probabilities across different paradigms. Assuming that the similarity choice model for identification is correct, it is straightforward to show that the choice axiom will hold if and only if the bias parameters and similarity parameters are invariant across paradigms. As noted by Townsend and Landon (1982), this type of parameter invariance is not a logical requirement of the choice model. Indeed, Nosofsky (1984b, in press) suggested that, since similarity is a function of selective attention to component stimulus dimensions, it is reasonable to expect the similarity parameters to change in systematic ways across different experimental contexts.

The preceding remarks about the choice model were intended to clear up some common misconceptions about the types of predictions it makes and its relation to other models. The main purpose of the present investigation is not to test the choice model, however. Rather, we follow a research strategy, outlined by Smith $(1980,1982)$, in which the choice model is used as an analytic device (see also Estes, 1982). Specifically, we shall define similarity in terms of the $\eta_{\mathrm{ij}}$ parameters in Equation 1. We will then go on to fit various restricted versions of the full choice model (Equation 1) to the identification data. These models are restricted in the sense that the similarity parameters in Equation 1 are constrained in various a priori ways. By comparing systematically the quantitative fits of these restricted models to that of the full choice model, we will be able to evaluate alternative hypotheses concerning the nature of separable-dimension interactions in determining overall similarity.

\section{METHOD}

\footnotetext{
The method has been discussed in detail elsewhere (Nosofsky, $1984 \mathrm{a}$, in press) and is only summarized here.

\section{Subjects and Apparatus}

Two subjects served as paid observers. A Tektronix 604 monitor interfaced with a PDP-11/10 computer was used to present the stimuli.

Stimuli were semicircles that varied in size (four levels) and angle of orientation of a radial line (four levels). The dimension values were combined orthogonally to yield a 16-member stimulus set (see
} 


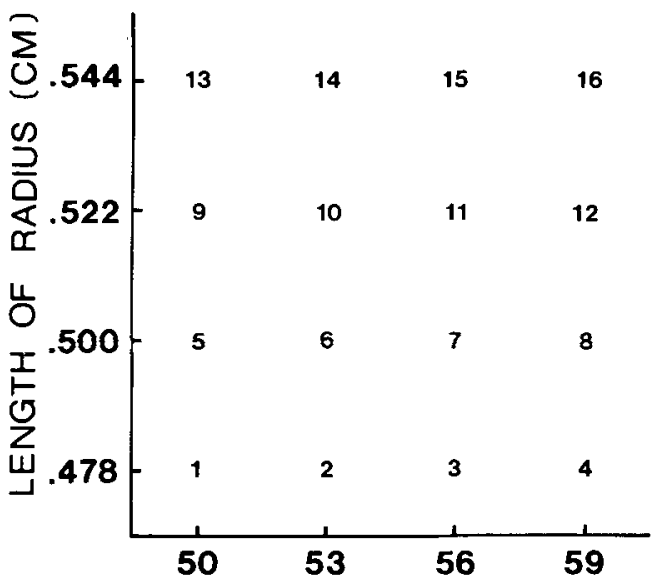

\section{ANGLE OF RADIAL LINE (DEGREES)}

Figure 2. Physical structure of the stimulus set along with the labels used for identifying the stimuli in this report.

Figure 2). Previous research indicates that stimuli like these are composed of separable dimensions (Garner \& Felfoldy, 1970; Shepard, 1964).

The center of each semicircle was located at the center of the Tektronix screen. A post-stimulus-pattern mask was used that consisted of a grid of points centered at the center of the screen.

\section{Procedure}

On any given trial, a fixation dot appeared at the center of the screen for $500 \mathrm{msec}$. A randomly selected stimulus was then presented for $150 \mathrm{msec}$ and was followed by the pattern mask. Following the subject's response, the correct answer was presented on the screen for $1 \mathrm{sec}$. There was a $500-\mathrm{msec}$ intertrial interval.

The size and angle dimensions were each given the labels 1 (smallest size, lowest angle) through 4 (largest size, highest angle). Subjects identified the stimuli by pressing one of 16 buttons arranged in a $4 \times 4$ grid. To enter angle $i$ and size $j$, the subject pressed the button in column $\mathrm{i}$ and row $\mathrm{j}$. Feedback on each trial consisted of a pair of numbers presented on the screen, the number on the left corresponding to angle and the number on the right to size.

Experimental sessions were organized into eight blocks of 100 trials, with summary feedback presented at the end of each block. Each subject completed 11 sessions. The theoretical analyses in the present report focus on the data obtained during Sessions 5-8. Sessions 1-4 are considered practice and Sessions 9-11 were run interspersed with another experimental condition in which subjects categorized the stimuli rather than identifying them [see Nosofsky (1984a, in press) for details].

\section{RESULTS}

Figure 3 plots the average percentage of correct identifications for size responses, angle responses, and overall identification responses (i.e., size and angle taken together on a given trial) as a function of sessions. The figure reveals slight improvements in identification performance over sessions. Table 1 reports the identification confusion data that are analyzed in the present report, namely those obtained during Sessions 5-8.

\section{THEORETICAL ANALYSIS}

\section{Dimensions Versus Overall Similarity}

An initial question that should be addressed concerns the appropriateness of using the choice model to account for the identification of separable-dimension stimuli. Garner $(1974,1976)$ argued that separable-dimension stimuli are perceived and classified in terms of their component dimensions rather than in terms of overall similarity relations. Indeed, a plausible hypothesis for the identification of separable-dimension stimuli is that subjects identify values on each component dimension independently and then combine these separate identifications into an overall response (Lockhead, 1972, p. 417). Such a model, which I shall term an independent-decisions

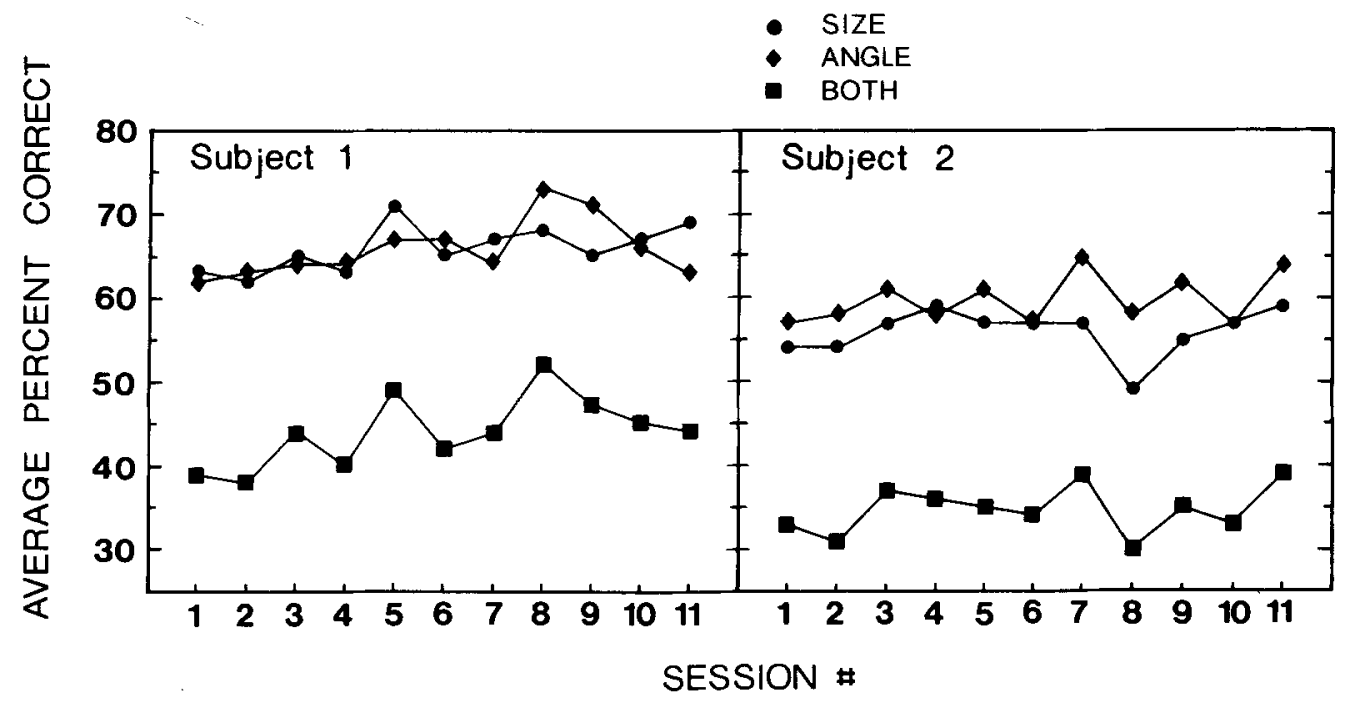

Figure 3. Percentage of correct size responses, angle responses, and overall identification responses as a function of sessions. 
Table 1

Observed and Predicted

Identification Confusion Frequencies

\begin{tabular}{|c|c|c|c|c|c|c|c|c|c|c|c|c|c|c|c|c|}
\hline & 1 & 2 & 3 & 4 & 5 & 6 & 7 & 8 & 9 & 10 & 11 & 12 & 13 & 14 & 15 & 16 \\
\hline \multicolumn{17}{|c|}{ Subject 1} \\
\hline \multirow{3}{*}{1} & & 34 & 0 & 0 & 66 & 15 & 0 & 0 & 4 & 1 & 0 & 0 & 0 & 0 & 0 & \\
\hline & 94 & 36 & 0 & 0 & 6 & 13 & 0 & 0 & 4 & & 0 & 0 & & & 0 & \\
\hline & 92 & & & & & & 0 & 0 & 3 & 0 & 0 & 0 & 0 & 0 & 0 & \\
\hline \multirow{3}{*}{2} & 13 & 85 & 34 & 1 & 12 & 35 & 20 & 3 & 1 & 1 & 0 & 0 & 0 & 0 & 0 & \\
\hline & 11 & 84 & 37 & 3 & 13 & 35 & 18 & 3 & 1 & & 0 & & & & 0 & \\
\hline & 11 & 84 & 40 & 2 & 13 & 34 & 19 & 1 & 1 & 1 & 0 & 0 & 0 & 0 & 0 & \\
\hline \multirow{3}{*}{3} & 0 & 15 & 79 & 30 & 2 & 9 & 36 & 17 & 0 & & 2 & & & & & \\
\hline & 0 & 12 & 79 & 3 & 1 & 8 & 37 & 1 & c & & & 0 & & & & \\
\hline & 0 & 14 & 74 & 36 & 0 & 8 & 41 & & 0 & 0 & 1 & 0 & 0 & 0 & 0 & \\
\hline \multirow{3}{*}{4} & 0 & 3 & 28 & 117 & 0 & 0 & 16 & 3 & c & $\mathrm{c}$ & 2 & 2 & 0 & & & \\
\hline & 0 & 1 & 24 & 117 & 0 & 0 & 17 & 4 & c & & 1 & & & & & \\
\hline & 0 & 0 & 25 & 116 & 0 & 0 & 17 & & 0 & ( & 0 & 1 & 0 & & & \\
\hline \multirow{3}{*}{5} & 11 & 8 & 0 & 0 & 121 & 22 & 2 & 0 & 46 & & 0 & 0 & 3 & & & \\
\hline & 12 & 7 & 1 & 0 & 121 & 23 & 2 & 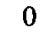 & 43 & & $c$ & & & & & \\
\hline & & 8 & 0 & 0 & & & 1 & & & & 0 & 0 & & 0 & & \\
\hline \multirow{3}{*}{6} & 0 & 14 & 9 & 0 & 16 & 47 & 38 & 0 & 8 & 21 & 12 & 2 & & & & c \\
\hline & 2 & 14 & 10 & 0 & 15 & 48 & 37 & 2 & 7 & 22 & 10 & 2 & & & & 0 \\
\hline & 1 & 14 & 9 & 1 & 15 & 52 & 35 & 4 & 7 & 19 & 9 & 1 & 0 & 0 & 0 & 0 \\
\hline \multirow{3}{*}{7} & 0 & 0 & 15 & 10 & 0 & 11 & 68 & 39 & 0 & 2 & 17 & 9 & 0 & & 0 & 0 \\
\hline & 0 & 2 & 14 & 9 & 0 & 12 & 68 & 40 & 0 & 4 & 1 & 7 & & & & \\
\hline & 0 & 2 & 15 & 9 & 0 & 11 & 63 & & 0 & 4 & 16 & 8 & 0 & 0 & 0 & $c$ \\
\hline \multirow{3}{*}{8} & 0 & 0 & 5 & 24 & 0 & 2 & 33 & 95 & 0 & 0 & 14 & 22 & 0 & 0 & 0 & \\
\hline & 0 & 0 & 5 & 1 & 0 & 0 & 3 & & & & & & ( & & & \\
\hline & 0 & 0 & 5 & & 0 & 1 & 32 & & & & & & & & & \\
\hline \multirow{3}{*}{9} & 0 & 0 & 0 & 0 & 18 & 4 & 0 & 0 & 135 & 24 & 3 & 0 & 3 & & & ( \\
\hline & 0 & 0 & 0 & c & 21 & 5 & 0 & 0 & 13 & 2 & & & & & & \\
\hline & 0 & 0 & 0 & 0 & 24 & 6 & 0 & 0 & 128 & 20 & 1 & 0 & 26 & 0 & 0 & 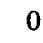 \\
\hline \multirow{3}{*}{10} & 0 & 0 & 0 & 0 & 6 & 19 & 11 & 3 & 29 & 79 & 32 & 5 & 6 & 15 & 12 & 0 \\
\hline & 0 & 0 & 0 & & 4 & 1 & 9 & 2 & 27 & 79 & 3. & 8 & & & 1( & 1 \\
\hline & 0 & 0 & 0 & c & 4 & 15 & 10 & 2 & 26 & & 40 & 5 & 4 & 18 & 9 & 1 \\
\hline \multirow{3}{*}{11} & 0 & 0 & 0 & 0 & 0 & 2 & 17 & 21 & 0 & 22 & 83 & 55 & 0 & 2 & 23 & 3 \\
\hline & 0 & 0 & 1 & & 0 & 4 & 19 & 2 & 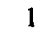 & 19 & & & 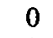 & 5 & & $J$ \\
\hline & 0 & 0 & 0 & 0 & 0 & 4 & 20 & & 1 & 2 & & & 0 & 4 & 17 & 5 \\
\hline \multirow{3}{*}{12} & 0 & 0 & 0 & 0 & 0 & 0 & 4 & & 0 & & 28 & & & & & 15 \\
\hline & 0 & 0 & 0 & & & 0 & 6 & & 0 & & & & & & & 17 \\
\hline & 0 & 0 & 0 & 0 & 0 & 0 & 6 & 29 & 0 & 1 & 33 & 103 & 0 & 0 & 9 & 17 \\
\hline \multirow{3}{*}{13} & 0 & 0 & 0 & 0 & 1 & 0 & 1 & & & 7 & & 0 & & & 1 & \\
\hline & 0 & 0 & 0 & 0 & & c & & & & & & & & & & \\
\hline & 0 & 0 & 0 & 0 & & 0 & 0 & 0 & & & & 0 & & & & \\
\hline \multirow{3}{*}{14} & 0 & 0 & 0 & 0 & 0 & 0 & 0 & 0 & 10 & 31 & 16 & 0 & 10 & 88 & 30 & 3 \\
\hline & 0 & 0 & 0 & $c$ & & & & & 8 & 2 & & & 1 & & & \\
\hline & 0 & 0 & 0 & 0 & & 0 & 0 & 0 & 0 & 26 & 10 & & 19 & 86 & 34 & 1 \\
\hline \multirow{3}{*}{15} & 0 & 0 & 0 & 0 & 0 & 0 & 0 & 0 & 0 & 7 & 23 & 27 & 0 & 19 & 97 & 32 \\
\hline & 0 & 0 & 0 & 0 & 0 & 0 & 0 & 0 & 0 & & & & & 19 & & 28 \\
\hline & 0 & 0 & 0 & 0 & 0 & 0 & 0 & & 0 & & & & 0 & 21 & 94 & 30 \\
\hline & 0 & 0 & 0 & 0 & 0 & 0 & 1 & 0 & 0 & 1 & 12 & 57 & 0 & 0 & 29 & 95 \\
\hline 16 & 0 & 0 & 0 & 0 & 0 & 0 & 1 & 0 & 0 & 1 & 10 & & 0 & 1 & 33 & \\
\hline & 0 & 0 & 0 & 0 & 0 & & 0 & 1 & 0 & 0 & 10 & 53 & 0 & 1 & 35 & 94 \\
\hline
\end{tabular}

Subject 2

$\begin{array}{rrrrrrrrrrrrrrrrr} & 118 & 11 & 0 & 0 & 42 & 8 & 1 & 0 & 3 & 3 & 1 & 0 & 1 & 0 & 0 & 0 \\ 1 & 118 & 20 & 2 & 0 & 34 & 9 & 1 & 0 & 2 & 2 & 1 & 0 & 0 & 0 & 0 & 0 \\ & 114 & 23 & 2 & 0 & 35 & 9 & 0 & 0 & 3 & 1 & 0 & 0 & 0 & 0 & 0 & 0 \\ & 54 & 58 & 11 & 3 & 22 & 22 & 8 & 2 & 1 & 4 & 2 & 0 & 0 & 1 & 0 & 0 \\ 2 & 45 & 58 & 14 & 3 & 19 & 32 & 7 & 1 & 2 & 3 & 2 & 0 & 0 & 0 & 0 & 0 \\ & 50 & 50 & 17 & 3 & 19 & 30 & 8 & 1 & 2 & 6 & 1 & 0 & 0 & 0 & 0 & 0\end{array}$


Table 1 (continued)

\begin{tabular}{|c|c|c|c|c|c|c|c|c|c|c|c|c|c|c|c|c|}
\hline & 1 & 2 & 3 & 4 & 5 & 6 & 7 & 8 & 9 & 10 & 11 & 12 & 13 & 14 & 15 & 16 \\
\hline \multicolumn{17}{|c|}{ Subject 2} \\
\hline 3 & $\begin{array}{r}10 \\
8 \\
7\end{array}$ & $\begin{array}{l}31 \\
28 \\
34\end{array}$ & $\begin{array}{l}66 \\
66 \\
64\end{array}$ & $\begin{array}{l}33 \\
35 \\
36\end{array}$ & $\begin{array}{l}4 \\
3 \\
2\end{array}$ & $\begin{array}{l}28 \\
23 \\
19\end{array}$ & $\begin{array}{l}27 \\
29 \\
29\end{array}$ & $\begin{array}{l}10 \\
15 \\
15\end{array}$ & $\begin{array}{l}0 \\
0 \\
0\end{array}$ & $\begin{array}{l}1 \\
1 \\
4\end{array}$ & $\begin{array}{l}5 \\
6 \\
6\end{array}$ & $\begin{array}{l}2 \\
2 \\
2\end{array}$ & $\begin{array}{l}0 \\
0 \\
0\end{array}$ & $\begin{array}{l}0 \\
0 \\
0\end{array}$ & $\begin{array}{l}0 \\
0 \\
0\end{array}$ & $\begin{array}{l}0 \\
0 \\
0\end{array}$ \\
\hline 4 & $\begin{array}{l}0 \\
0 \\
0\end{array}$ & $\begin{array}{l}6 \\
6 \\
5\end{array}$ & $\begin{array}{l}38 \\
36 \\
37\end{array}$ & $\begin{array}{l}69 \\
69 \\
65\end{array}$ & $\begin{array}{l}0 \\
0 \\
0\end{array}$ & $\begin{array}{l}7 \\
7 \\
5\end{array}$ & $\begin{array}{l}24 \\
24 \\
28\end{array}$ & $\begin{array}{l}45 \\
48 \\
53\end{array}$ & $\begin{array}{l}0 \\
0 \\
0\end{array}$ & $\begin{array}{l}2 \\
2 \\
1\end{array}$ & $\begin{array}{l}9 \\
7 \\
9\end{array}$ & $\begin{array}{r}9 \\
10 \\
7\end{array}$ & $\begin{array}{l}0 \\
0 \\
0\end{array}$ & $\begin{array}{l}0 \\
0 \\
0\end{array}$ & $\begin{array}{l}2 \\
2 \\
0\end{array}$ & $\begin{array}{l}0 \\
1 \\
0\end{array}$ \\
\hline 5 & $\begin{array}{l}30 \\
38 \\
39\end{array}$ & $\begin{array}{r}7 \\
10 \\
9\end{array}$ & $\begin{array}{l}0 \\
1 \\
0\end{array}$ & $\begin{array}{l}0 \\
0 \\
0\end{array}$ & $\begin{array}{l}71 \\
71 \\
71\end{array}$ & $\begin{array}{l}21 \\
17 \\
18\end{array}$ & $\begin{array}{l}3 \\
1\end{array}$ & $\begin{array}{l}0 \\
0 \\
0\end{array}$ & $\begin{array}{l}37 \\
27 \\
26\end{array}$ & $\begin{array}{r}7 \\
9 \\
10\end{array}$ & $\begin{array}{l}0 \\
0 \\
0\end{array}$ & $\begin{array}{l}1 \\
0 \\
0\end{array}$ & $\begin{array}{l}1 \\
1 \\
0\end{array}$ & $\begin{array}{l}0 \\
1 \\
1\end{array}$ & $\begin{array}{l}0 \\
0 \\
0\end{array}$ & $\begin{array}{l}0 \\
0 \\
0\end{array}$ \\
\hline 6 & $\begin{array}{l}15 \\
14 \\
15\end{array}$ & $\begin{array}{l}34 \\
24 \\
22\end{array}$ & $\begin{array}{l}4 \\
9 \\
7\end{array}$ & $\begin{array}{l}2 \\
2 \\
2\end{array}$ & $\begin{array}{l}21 \\
25 \\
25\end{array}$ & $\begin{array}{l}45 \\
45 \\
49\end{array}$ & $\begin{array}{l}13 \\
12 \\
15\end{array}$ & 2 & $\begin{array}{r}8 \\
9 \\
10\end{array}$ & $\begin{array}{l}35 \\
38 \\
33\end{array}$ & $\begin{array}{l}6 \\
5 \\
8\end{array}$ & $\begin{array}{l}0 \\
0 \\
1\end{array}$ & $\begin{array}{l}0 \\
1 \\
1\end{array}$ & $\begin{array}{l}5 \\
4 \\
3\end{array}$ & $\begin{array}{l}2 \\
2 \\
1\end{array}$ & $\begin{array}{l}0 \\
0 \\
0\end{array}$ \\
\hline 7 & $\begin{array}{l}1 \\
1 \\
1\end{array}$ & $\begin{array}{l}7 \\
8 \\
9\end{array}$ & $\begin{array}{l}17 \\
15 \\
15\end{array}$ & $\begin{array}{l}12 \\
12 \\
14\end{array}$ & $\begin{array}{l}1 \\
3 \\
2\end{array}$ & $\begin{array}{l}17 \\
18 \\
23\end{array}$ & $\begin{array}{l}52 \\
52 \\
43\end{array}$ & $\begin{array}{l}37 \\
32 \\
32\end{array}$ & $\begin{array}{l}0 \\
1 \\
1\end{array}$ & $\begin{array}{l}19 \\
18 \\
17\end{array}$ & & $\begin{array}{l}14 \\
12 \\
14\end{array}$ & 0 & $\begin{array}{l}1 \\
2 \\
2\end{array}$ & $\begin{array}{l}1 \\
2 \\
5\end{array}$ & $\begin{array}{l}1 \\
2 \\
1\end{array}$ \\
\hline 8 & $\begin{array}{l}0 \\
0 \\
0\end{array}$ & $\begin{array}{l}0 \\
1 \\
1\end{array}$ & $\begin{array}{r}11 \\
6 \\
6\end{array}$ & $\begin{array}{l}20 \\
17 \\
20\end{array}$ & $\begin{array}{l}0 \\
0 \\
0\end{array}$ & 3 & $\begin{array}{l}19 \\
24 \\
24\end{array}$ & $\begin{array}{l}84 \\
84 \\
78\end{array}$ & $\begin{array}{l}0 \\
0 \\
0\end{array}$ & $\begin{array}{l}3 \\
3 \\
2\end{array}$ & $\begin{array}{l}26 \\
27 \\
25\end{array}$ & $\begin{array}{l}36 \\
37 \\
39\end{array}$ & $\begin{array}{l}0 \\
0 \\
0\end{array}$ & $\begin{array}{l}0 \\
0 \\
0\end{array}$ & $\begin{array}{l}6 \\
5 \\
6\end{array}$ & $\begin{array}{l}0 \\
2 \\
3\end{array}$ \\
\hline 9 & $\begin{array}{l}4 \\
5 \\
6\end{array}$ & $\begin{array}{l}3 \\
2 \\
2\end{array}$ & $\begin{array}{l}0 \\
0 \\
0\end{array}$ & $\begin{array}{l}0 \\
0 \\
0\end{array}$ & $\begin{array}{l}46 \\
56 \\
54\end{array}$ & $\begin{array}{l}14 \\
13 \\
14\end{array}$ & $\begin{array}{l}2 \\
1 \\
1\end{array}$ & $\begin{array}{l}0 \\
0 \\
0\end{array}$ & $\begin{array}{l}75 \\
75 \\
74\end{array}$ & $\begin{array}{l}22 \\
26 \\
26\end{array}$ & $\begin{array}{l}0 \\
0 \\
1\end{array}$ & $\begin{array}{l}1 \\
1 \\
0\end{array}$ & & $\begin{array}{r}11 \\
7 \\
7\end{array}$ & $\begin{array}{l}1 \\
0 \\
0\end{array}$ & $\begin{array}{l}0 \\
0 \\
0\end{array}$ \\
\hline 10 & $\begin{array}{l}3 \\
4 \\
2\end{array}$ & $\begin{array}{l}2 \\
3 \\
5\end{array}$ & $\begin{array}{l}1 \\
1 \\
1\end{array}$ & $\begin{array}{l}0 \\
1 \\
0\end{array}$ & $\begin{array}{l}15 \\
13 \\
15\end{array}$ & $\begin{array}{l}41 \\
38 \\
34\end{array}$ & & $\begin{array}{l}2 \\
2 \\
2\end{array}$ & $\begin{array}{l}22 \\
18 \\
18\end{array}$ & $\begin{array}{l}62 \\
62 \\
62\end{array}$ & $\begin{array}{l}12 \\
18 \\
15\end{array}$ & $\begin{array}{l}4 \\
2 \\
3\end{array}$ & $\begin{array}{l}7 \\
5 \\
5\end{array}$ & & $\begin{array}{l}5 \\
6 \\
6\end{array}$ & $\begin{array}{l}0 \\
0 \\
0\end{array}$ \\
\hline 11 & $\begin{array}{l}1 \\
1 \\
0\end{array}$ & $\begin{array}{l}2 \\
2 \\
1\end{array}$ & $\begin{array}{l}3 \\
2 \\
3\end{array}$ & $\begin{array}{l}1 \\
3 \\
4\end{array}$ & $\begin{array}{l}0 \\
0 \\
1\end{array}$ & $\begin{array}{r}4 \\
5 \\
10\end{array}$ & $\begin{array}{l}30 \\
27 \\
25\end{array}$ & $\begin{array}{l}32 \\
31 \\
28\end{array}$ & $\begin{array}{l}0 \\
0\end{array}$ & & & & $\begin{array}{l}0 \\
0 \\
0\end{array}$ & $\begin{array}{r}10 \\
8 \\
8\end{array}$ & $\begin{array}{l}21 \\
20 \\
22\end{array}$ & $\begin{array}{l}2 \\
6 \\
5\end{array}$ \\
\hline 12 & $\begin{array}{l}0 \\
0 \\
0\end{array}$ & $\begin{array}{l}0 \\
0 \\
0\end{array}$ & $\begin{array}{l}1 \\
1 \\
1\end{array}$ & $\begin{array}{l}5 \\
4 \\
3\end{array}$ & $\begin{array}{l}0 \\
1 \\
0\end{array}$ & $\begin{array}{l}1 \\
1 \\
1\end{array}$ & $\begin{array}{r}8 \\
10 \\
11\end{array}$ & $\begin{array}{l}39 \\
38 \\
40\end{array}$ & 0 & $\begin{array}{l}1 \\
3 \\
3\end{array}$ & $\begin{array}{l}32 \\
26 \\
29\end{array}$ & $\begin{array}{l}64 \\
64 \\
61\end{array}$ & & $\begin{array}{l}0 \\
2 \\
2\end{array}$ & $\begin{array}{l}26 \\
29 \\
24\end{array}$ & $\begin{array}{l}17 \\
16 \\
19\end{array}$ \\
\hline 13 & $\begin{array}{l}0 \\
1 \\
0\end{array}$ & $\begin{array}{l}0 \\
0 \\
0\end{array}$ & $\begin{array}{l}0 \\
0 \\
0\end{array}$ & $\begin{array}{l}0 \\
0 \\
0\end{array}$ & $\begin{array}{r}10 \\
9 \\
10\end{array}$ & $\begin{array}{l}5 \\
4 \\
3\end{array}$ & $\begin{array}{l}0 \\
0 \\
0\end{array}$ & $\begin{array}{l}0 \\
0\end{array}$ & $\begin{array}{l}47 \\
54 \\
56\end{array}$ & $\begin{array}{l}24 \\
25 \\
23\end{array}$ & $\begin{array}{l}0 \\
0 \\
1\end{array}$ & $\begin{array}{l}0 \\
0 \\
0\end{array}$ & $\begin{array}{l}69 \\
69 \\
67\end{array}$ & $\begin{array}{l}35 \\
28 \\
31\end{array}$ & $\begin{array}{l}3 \\
2 \\
1\end{array}$ & $\begin{array}{l}0 \\
0 \\
0\end{array}$ \\
\hline 14 & $\begin{array}{l}0 \\
0 \\
0\end{array}$ & $\begin{array}{l}0 \\
1 \\
0\end{array}$ & $\begin{array}{l}0 \\
0 \\
0\end{array}$ & $\begin{array}{l}0 \\
0 \\
0\end{array}$ & $\begin{array}{l}4 \\
3 \\
2\end{array}$ & $\begin{array}{r}9 \\
10 \\
8\end{array}$ & $\begin{array}{l}4 \\
3 \\
4\end{array}$ & $\begin{array}{l}1 \\
1 \\
1\end{array}$ & $\begin{array}{r}9 \\
13 \\
12\end{array}$ & $\begin{array}{l}45 \\
44 \\
49\end{array}$ & $\begin{array}{l}14 \\
16 \\
15\end{array}$ & $\begin{array}{l}5 \\
3 \\
4\end{array}$ & $\begin{array}{r}8 \\
14 \\
16\end{array}$ & $\begin{array}{l}77 \\
77 \\
74\end{array}$ & $\begin{array}{l}37 \\
30 \\
28\end{array}$ & $\begin{array}{l}3 \\
2 \\
3\end{array}$ \\
\hline 15 & $\begin{array}{l}0 \\
0 \\
0\end{array}$ & $\begin{array}{l}0 \\
0 \\
0\end{array}$ & $\begin{array}{l}0 \\
0 \\
0\end{array}$ & $\begin{array}{l}1 \\
1 \\
0\end{array}$ & $\begin{array}{l}0 \\
0 \\
0\end{array}$ & $\begin{array}{l}2 \\
2 \\
2\end{array}$ & $\begin{array}{l}3 \\
2 \\
5\end{array}$ & $\begin{array}{l}7 \\
8 \\
9\end{array}$ & $\begin{array}{l}0 \\
1 \\
0\end{array}$ & $\begin{array}{l}11 \\
10 \\
10\end{array}$ & $\begin{array}{l}26 \\
27 \\
29\end{array}$ & $\begin{array}{l}47 \\
44 \\
36\end{array}$ & $\begin{array}{l}0 \\
1 \\
0\end{array}$ & $\begin{array}{l}13 \\
20 \\
19\end{array}$ & $\begin{array}{l}60 \\
60 \\
65\end{array}$ & $\begin{array}{l}39 \\
33 \\
33\end{array}$ \\
\hline 16 & $\begin{array}{l}0 \\
0 \\
0\end{array}$ & $\begin{array}{l}0 \\
0 \\
0\end{array}$ & $\begin{array}{l}0 \\
0 \\
0\end{array}$ & $\begin{array}{l}1 \\
0 \\
0\end{array}$ & $\begin{array}{l}0 \\
0 \\
0\end{array}$ & $\begin{array}{l}1 \\
1 \\
0\end{array}$ & $\begin{array}{l}3 \\
3 \\
1\end{array}$ & $\begin{array}{l}7 \\
5 \\
6\end{array}$ & $\begin{array}{l}0 \\
0 \\
0\end{array}$ & $\begin{array}{l}0 \\
0 \\
1\end{array}$ & $\begin{array}{l}17 \\
13 \\
10\end{array}$ & $\begin{array}{l}34 \\
35 \\
39\end{array}$ & $\begin{array}{l}0 \\
0 \\
0\end{array}$ & $\begin{array}{l}1 \\
2 \\
3\end{array}$ & $\begin{array}{l}40 \\
46 \\
46\end{array}$ & $\begin{array}{l}84 \\
84 \\
82\end{array}$ \\
\hline
\end{tabular}

Note-Rows correspond to stimuli and columns correspond to response. Top line in each row, observed confusion frequencies; middle line, full-choice model predicted confusion frequencies; bottom line, MDS-choice model predicted confusion frequencies.

model, seems particularly plausible under the current experimental conditions in which subjects identified stimuli by giving two-dimensional responses. An independentdecisions model seems contrary in spirit to the choice model approach, where overall similarity relations among stimulus wholes determine identification performance. Yet, as will now be shown, if the choice model characterized accurately identification performance along each individual component dimension, then the independentdecisions model would be a special case of the general choice model.

To simplify the discussion, a two-dimensional stimulus set is assumed, the extension to $\mathrm{n}$ dimensions being straightforward. Also, it is assumed that the stimulus set is constructed by combining orthogonally the values along each component dimension (as in the present study). A stimulus having level $i$ on dimension 1 and level $u$ on dimension 2 will be denoted $S_{i u}$.

According to the choice model, the probability of making response pair $R_{j v}$ given dimension pair $S_{i u}$ is given by

$$
\mathrm{P}\left(\mathrm{R}_{\mathrm{jv}} \mid \mathbf{S}_{\mathrm{iu}}\right)=\frac{\mathrm{b}_{\mathrm{jv}} \eta_{\mathrm{iu}, \mathrm{jv}}}{\sum_{\mathrm{kw}} \mathrm{b}_{\mathrm{kw}} \eta_{\mathrm{iu}, \mathrm{kw}}},
$$

where $0 \leq b_{\mathrm{jv}} \leq 1, \Sigma \mathrm{b}_{\mathrm{jv}}=1, \eta_{\mathrm{iu}, \mathrm{jv}}=\eta_{\mathrm{jv}, \mathrm{iu}}$, and $\eta_{\mathrm{iu}, \mathrm{iu}}=1$. The parameter $b_{j v}$ is the bias for making response pair 
$\mathbf{R}_{\mathrm{jv}}$, and the parameter $\eta_{\mathrm{iu}, \mathrm{jv}}$ is the similarity between dimension pairs $S_{i u}$ and $S_{j v}$. Equation 2 is the same as Equation 1, except that the two-dimensional structure of the stimulus set is now made explicit in the notation.

Suppose, instead, that the choice model characterized accurately identification performance for each dimension taken separately. In other words, the probability of making response $\mathrm{j}$ given level $\mathrm{i}$ on dimension 1 is given by

$$
\mathbf{P}^{(1)}\left(\mathbf{R}_{\mathrm{j}} \mid \mathrm{S}_{\mathrm{i}}\right)=\frac{\mathbf{b}_{\mathrm{j}}^{(1)} \eta_{\mathrm{ij}}^{(1)}}{\sum_{\mathbf{k}} \mathbf{b}_{\mathrm{k}}^{(1)} \eta_{\mathrm{ik}}^{(1)}},
$$

where $0 \leq b_{j}^{(1)} \leq 1, \Sigma b_{j}^{(1)}=1, \eta_{\mathrm{ij}}^{(1)}=\eta_{\mathrm{ji}}^{(1)}$, and $\eta_{\mathrm{ii}}^{(1)}$ $=1$. The parameters are superscripted to make clear that we are referring to choices along dimension 1. Analogously, the probability of making response $v$ given stimulus level $u$ on dimension 2 is given by

$$
\mathrm{P}^{(2)}\left(\mathrm{R}_{\mathrm{v}} \mid \mathrm{S}_{\mathrm{u}}\right)=\frac{\mathrm{b}_{\mathrm{v}}^{(2)} \eta_{\mathrm{uv}}^{(2)}}{\sum_{\mathrm{w}} \mathrm{b}_{\mathrm{w}}^{(2)} \eta_{\mathrm{uw}}^{(2)}}
$$

According to the independent-decisions model, the probability of making response pair $\mathbf{R}_{\mathbf{j v}}$ given dimension pair $S_{\text {iu }}$ is given by

$$
P\left(R_{j v} \mid S_{i u}\right)=P^{(1)}\left(R_{j} \mid S_{i}\right) P^{(2)}\left(R_{v} \mid S_{u}\right)
$$

Substituting the expressions in Equations $3 a$ and $3 b$ into Equation 4 yields

$$
\begin{aligned}
\mathrm{P}\left(\mathrm{R}_{\mathrm{jv}} \mid S_{\mathrm{iu}}\right) & =\frac{\mathrm{b}_{\mathrm{j}}^{(1)} \eta_{\mathrm{ij}}^{(1)}}{\sum_{\mathrm{k}} \mathrm{b}_{\mathrm{k}}^{(1)} \eta_{\mathrm{ik}}^{(1)}} \frac{\mathrm{b}_{\mathrm{v}}^{(2)} \eta_{\mathrm{uv}}^{(2)}}{\sum_{\mathrm{w}} \mathrm{b}_{\mathrm{w}}^{(2)} \eta_{\mathrm{uw}}^{(2)}} \\
& =\frac{\mathrm{b}_{\mathrm{j}}^{(1)} \mathrm{b}_{\mathrm{v}}^{(2)} \eta_{\mathrm{ij}}^{(1)} \eta_{\mathrm{uv}}^{(2)}}{\sum_{\mathrm{k}} \sum_{\mathrm{w}}\left[\mathrm{b}_{\mathrm{k}}^{(1)} b_{\mathrm{w}}^{(2)} \eta_{\mathrm{ik}}^{(1)} \eta_{\mathrm{uw}}^{(2)}\right]} .
\end{aligned}
$$

Equation 5 is a special case of the general choice model formalized in Equation 2, as can be seen by setting

$$
\begin{aligned}
b_{\mathrm{jv}} & =b_{\mathrm{j}}^{(1)} \mathrm{b}_{\mathrm{v}}^{(2)} \\
\eta_{\mathrm{iu}, \mathrm{jv}} & =\eta_{\mathrm{ij}}^{(1)} \eta_{\mathrm{uv}}^{(2)} .
\end{aligned}
$$

Note that the various parameter constraints are satisfied, since

$$
\begin{gathered}
\eta_{\mathrm{iu}, \mathrm{iu}}=\eta_{\mathrm{ii}}^{(1)} \eta_{\mathrm{uu}}^{(2)}=1 \cdot 1=1 \\
\eta_{\mathrm{iu}, \mathrm{jv}}=\eta_{\mathrm{ij}}^{(1)} \eta_{\mathrm{uv}}^{(2)}=\eta_{\mathrm{ji}}^{(1)} \eta_{\mathrm{vu}}^{(2)}=\eta_{\mathrm{jv}, \mathrm{iu}}
\end{gathered}
$$

To summarize, then, if the stimulus set is constructed by combining orthogonally the values along each component dimension, and if the choice model characterizes accurately identification performance along each individual component dimension, the independent-decisions model turns out to be a special case of the general choice model. It is remarkable that two models based on such different underlying intuitions are, from a formal point of view, so closely linked. ${ }^{3}$

\section{Fits of the Choice Model to the Identification Data}

The full choice model (Equation 1) was fitted to the identification confusion data using a maximum-likelihood criterion (see Smith, 1982, Appendix B). The predicted confusion frequencies are shown rounded to the nearest integer, along with the observed frequencies, in Table 1. A scatterplot of the observed confusion frequencies against the predicted confusion frequencies is shown in Figure 4 (top panel). The model accounts for $99.4 \%$ of the variance in Subject 1's data and for $98.2 \%$ of the variance in Subject 2's data. Although most of the variance has been accounted for, it should be acknowledged that the discrepancies between the predicted and observed confusion frequencies are statistically significant. An unfortunate problem here is the large number of zero entries in the confusion matrices. Technically, one degree of freedom is lost from the data each time a pair of stimuli is never confused. Irrespective of statistical tests of overall goodness of fit, it appears that the choice model will be competitive with alternative models and should serve satisfactorily as a framework within which to analyze further the identification confusion data.

The good fit of the full choice model comes at a price, namely the very large number of parameters that needed to be estimated. Assuming $\mathbf{n}$ stimuli in an identification experiment, the model uses $n(n-1) / 2$ freely varying similarity parameters (120 in the present situation), and $n-1$ freely varying response bias parameters (15 in the present situation). Therefore, in the remainder of this article, various restricted versions of the full choice model are fitted to the data. These restricted models, of course, can do no better than the full choice model in terms of overall goodness of fit; however, they offer the possibility of achieving a more parsimonious account of the identification confusion data. More important, as explained in the introduction, tests of these restricted models can provide insight into the psychological processes and similarity structure that governed the subjects' choices.

A standard statistical technique known as likelihoodratio testing can be used to determine whether the fit of a restricted model is significantly worse than that of a more general unrestricted one [see Wickens (1982, chap. 6) for an excellent exposition of this technique]. Let $\mathrm{L}$ be the likelihood of a data set given the maximumlikelihood parameters in the unrestricted model, and let $L^{*}$ be the likelihood of the data set given the parameters in the restricted model. Assuming the restricted model is correct, then, for large sample size, the quantity $\chi^{2}=2\left(\ln L-\ln L^{*}\right)$ has approximately a chi-square distribution with degrees of freedom equal to the number of parameters that were constrained in moving from the unrestricted to the restricted model. If this quantity exceeds the critical value of chi-square, then the restricted model is rejected as being significantly worse than the unrestricted one. It should be noted that a test of the overall goodness of fit of a model is a special case of likelihoodratio testing. In particular, the likelihood of the data set, 


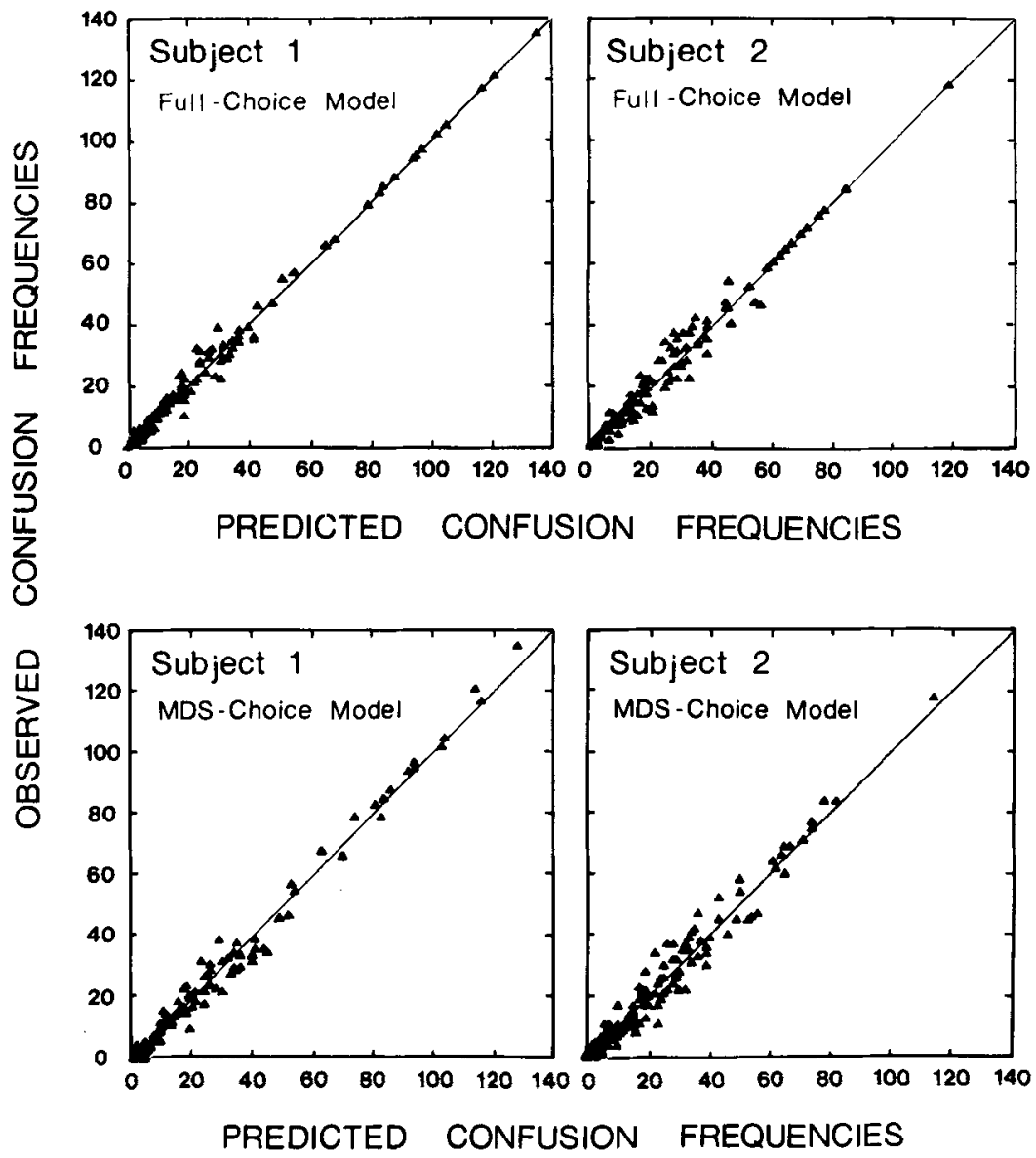

Figure 4. Observed confusion frequencies plotted against predicted confusion frequencies. Top panel: Full choice model. Bottom panel: MDS-choice model.

given the parameters in the model, is compared with the likelihood of the data set given a more general model that fits the data perfectly. For conciseness, the log-likelihood values for the perfect-fitting model, the full choice model, and the various restricted choice models that will now be considered are all summarized in Table 2.

\section{Independent-Decisions Choice Model}

The first restricted model is simply the independentdecisions choice model given by Equation 5 . As the reader may verify, the model uses only 12 freely varying similarity parameters ( 6 per dimension) and 6 freely varying response bias parameters ( 3 per dimension). The fit of the independent-decisions choice model is significantly worse than that of the full choice model for both Subject 1 $\left[\chi^{2}(117)=145.6, p<.05\right]$ and Subject $2\left[\chi^{2}(117)=\right.$ $312.7, \mathrm{p}<.01]$, suggesting that the subjects' multidimensional identification choices were not simply some independent combination of unidimensional identification choices. Later, we will have reason to reconsider the independent-decisions choice model and discover where its shortcomings lie.

\section{Multidimensional Scaling Approach}

A classic approach to modeling stimulus similarity is multidimensional scaling theory. In this approach, stimuli are represented as points in a multidimensional space and similarity is assumed to be some monotonically decreasing function of distance in the space. The multidimensional scaling approach offers a straightforward means by which to reduce the number of similarity parameters used in the full choice model. Indeed, this is the approach suggested and tested by Shepard $(1957,1958 \mathrm{~b})$ in the original formulation of the choice model. The underlying asumption is that

$$
\eta_{\mathrm{ij}}=\mathrm{f}\left(\mathrm{d}_{\mathrm{ij}}\right) \text {, }
$$

where $\mathrm{f}$ is some monotonically decreasing function and where $d_{i j}$ is the distance between the points representing stimuli $i$ and $j$. In the present situation there are 16 stimuli that will be represented as points in a two-dimensional space. Thus, the $120 \eta_{\mathrm{ij}}$ similarity parameters in the full choice model will be replaced by only 32 coordinate parameters. (Actually, there are only 30 freely varying 
Table 2

Summary of Model Fits

\begin{tabular}{|c|c|c|c|c|}
\hline Model & $\begin{array}{c}\begin{array}{c}\text { Number of } \\
\text { Free }\end{array} \\
\text { Parameters }\end{array}$ & $\ln \mathrm{L}$ & SSE & $\begin{array}{c}\% \\
\text { Variance } \\
\end{array}$ \\
\hline \multicolumn{5}{|c|}{ Subject 1} \\
\hline Perfect-Fitting & 240 & -215.62 & 0 & 100.0 \\
\hline Full Choice & 135 & -263.12 & 948 & 99.4 \\
\hline $\begin{array}{l}\text { Independent- } \\
\text { Decisions Choice }\end{array}$ & 18 & -335.94 & 4,564 & 97.0 \\
\hline $\begin{array}{l}\text { Unconstrained } \\
\text { MDS-Choice }\end{array}$ & 45 & -293.82 & 1,510 & 99.0 \\
\hline $\begin{array}{l}\text { Constrained } \\
\text { MDS-Choice }\end{array}$ & 21 & -311.12 & 2,344 & 98.5 \\
\hline \multicolumn{5}{|c|}{ Subject 2} \\
\hline Perfect-Fitting & 240 & -290.66 & 0 & 100.0 \\
\hline Full Choice & 135 & -359.30 & 1,736 & 98.2 \\
\hline $\begin{array}{l}\text { Independent- } \\
\text { Decisions Choice }\end{array}$ & 18 & -515.65 & 7,765 & 92.0 \\
\hline $\begin{array}{l}\text { Unconstrained } \\
\text { MDS-Choice }\end{array}$ & 45 & -406.21 & 2,645 & 97.3 \\
\hline $\begin{array}{l}\text { Constrained } \\
\text { MDS-Choice }\end{array}$ & 21 & -464.31 & 4,928 & 94.9 \\
\hline
\end{tabular}

Note $-\ln L=\log$ likelihood. SSE = sum of squared deviations between observed and predicted confusion frequencies.

coordinate parameters, since distance relationships are invariant under horizontal and vertical translations of the space.) Equations 1 and 8 taken together will be referred to as the MDS-choice model.

The MDS-choice model has provided excellent quantitative fits to data in previous tests (e.g., Getty et al., 1979; Holyoak \& Glass, 1978; Nosofsky, 1985a, 1985b; Shepard, 1958b; see also Monahan \& Lockhead, 1977, for some closely related work). However, these previous tests used stimuli that either varied along a single unidimensional continuum or were composed of integral dimensions. To my knowledge, the present report represents a first attempt at fitting the MDS-choice model to confusion data obtained when subjects identified separable-dimension stimuli.

To implement the MDS-choice model, two decisions need to be made. First, what is the distance function for computing psychological distance relationships? Second, what is the function $f$ for relating stimulus similarity to psychological distance?

The distance function was assumed to take the form of the Minkowski r-metric:

$$
\mathrm{d}_{\mathrm{ij}}=\left[\sum_{\mathbf{k}=1}^{2}\left|\mathrm{x}_{\mathrm{ik}}-\mathrm{x}_{\mathrm{jk}}\right|^{\mathrm{r}}\right]^{1 / \mathrm{r}},
$$

where $\mathrm{x}_{\mathrm{ik}}$ is the (psychological) value of stimulus $\mathrm{i}$ on dimension $k$. Of course, the city-block metric $(r=1)$ and Euclidean metric $(r=2)$ are special cases of Equation 9.

Two functions for relating stimulus similarity to psychological distance were considered. The first was an exponential decay function:

$$
\eta_{\mathrm{ij}}=\mathrm{e}^{-\mathrm{d}_{\mathrm{ij}}} .
$$

The second was Gaussian in form:

$$
\eta_{\mathrm{ij}}=\mathrm{e}^{-\mathrm{d}_{\mathrm{ij}}^{2}} .
$$

The choice of these two functions was based on previous theoretical and empirical considerations (Nosofsky, 1985b; Shepard, 1958a, 1958b, 1984) and on preliminary analyses of the identification data obtained in the present study.

Now, obviously, to determine the best-fitting r-metric and similarity function, one must compute a concomitant MDS solution for the stimulus set. Unfortunately, the computational task of finding the best-fitting twodimensional solution for each value of $r$ and each similarity function would be enormous. To gain insight into which value of $r$ and which similarity function seemed most promising, therefore, a series of constrained twodimensional solutions were first fitted to the data.

In the constrained two-dimensional solution, one's knowledge of the physical definition of the stimulus set is used to further reduce the number of parameters that need to be estimated. In particular, all stimuli sharing a common physical value of angle are assumed to have the same first coordinate $\left(\mathrm{x}_{\mathrm{i} 1}\right)$. Likewise, all stimuli sharing a common physical value of size are assumed to have the same second coordinate $\left(\mathrm{x}_{\mathrm{i} 2}\right)$. Since there are four levels of angle and four levels of size, and the coordinates corresponding to the lowest level on each dimension may be arbitrarily set equal to 0 (translation invariance), there are only six free coordinate parameters.

The value of $r$ in the Minkowski r-metric formula was varied from .8 to 2.4 in increments of .2. For each value of $r$ and each similarity function, the constrained twodimensional solution that provided a maximum-likelihood fit to the identification data (using the MDS-choice model-Equations 1,9, and 10) was computed. A general parameter search routine was used to obtain the maximumlikelihood coordinate parameters, with several starting configurations used in each search to guard against local minima. The bias parameters in Equation 1 were held fixed at those values that provided a best fit of the full choice model to the identification data. The results of the analysis are shown in Figure 5.

It is clear from inspection that the constrained MDSchoice model accounts best for the identification data by assuming a Gaussian similarity function and a value of $r$ in the Minkowski r-metric formula somewhere in the neighborhood of 2. Except for very low values of $r$, where the fit is poor regardless of which similarity function is used, the Gaussian similarity function does markedly better than the exponential decay function. And, assuming the Gaussian similarity function, the improvement in fit that is obtained as the value of $r$ increases from 1 to 2 is dramatic, with a reduction in chi-square of over 400 for both subjects. Since there is little change in overall fit in the neighborhood of $r=2$, and this value is conventional, the standard Euclidean distance metric will be assumed in subsequent analyses.

A graphical comparison of the alternative similarity functions and distance metrics is provided for Subject 1 


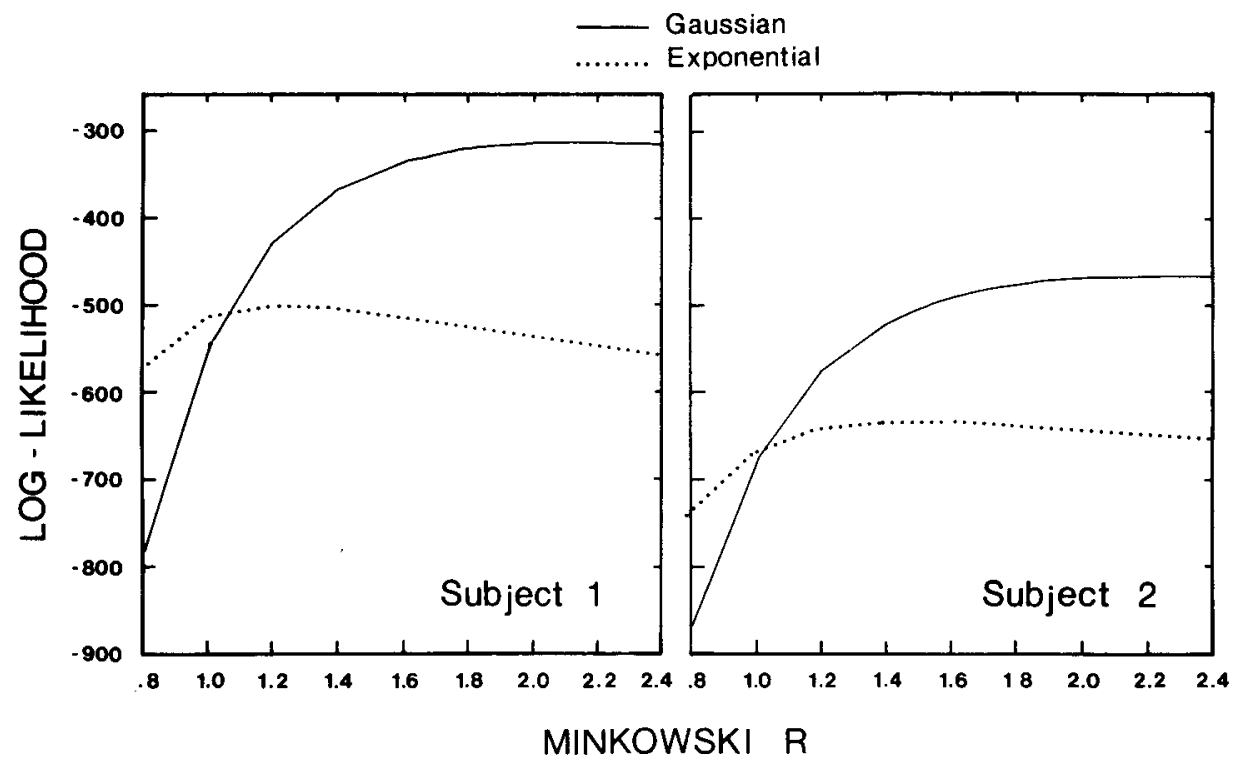

Figure 5. Log-likelihood values for the constrained MDS-choice model plotted as a function of $r$ for each similarity function.

in Figure 6. (We restrict attention here to the Euclidean and city-block distance metrics.) In each graph, the maximum-likelihood $\eta_{\mathrm{ij}}$ similarity parameters for the full choice model are plotted against a set of corresponding distance values $\left(\mathrm{d}_{\mathrm{ij}}\right)$. These distance values were computed from the scaling solutions that provided a maximumlikelihood fit of the constrained MDS-choice model to the identification data. Four such sets of distance values were computed-one from the scaling solution in which a Gaussian similarity function and a Euclidean distance metric were assumed, a second from the scaling solution in which a Gaussian similarity function and a city-block distance metric were assumed, and so forth. The solid curve in each graph is the theoretical function for relating similarity to psychological distance. It is evident from inspection that the Gaussian-Euclidean model captures the underlying similarity structure far better than any of the alternative models shown in Figure 6.

The graphs are useful for illustrating precisely wherein the alternative models fail. Four types of stimulus pairs have been distinguished. One-dimensional one-link pairs refer to pairs of stimuli differing by one level along one dimension (e.g., dimension-pairs $[2,2]$ and $[3,2])$. Onedimensional two-link pairs refer to pairs of stimuli differing by two levels along one dimension (e.g., $[2,2]$ and $[4,2])$. Two-dimensional two-link pairs refer to pairs of stimuli differing by one level along both dimensions (e.g., $[2,2]$ and $[3,3])$. And "Others" refers to all remaining types of stimulus pairs.

The graphs show that the alternative similarity function/distance metric combinations (with the exception of the Gaussian-Euclidean) systematically overestimate or underestimate similarity relations for the various pairs of stimuli defined above. The comparison between onedimensional two-link pairs and two-dimensional two-link pairs is particularly instructive for pointing up the shortcomings of the city-block distance metric. According to the city-block metric, the members of these pairs are separated by approximately the same distance and, therefore, should be approximately equally similar. The observed similarity relations are in direct contrast to this prediction, however, with the members of two-dimensional twolink pairs being consistently more similar to one another than the members of one-dimensional two-link pairs. The graphs also illustrate that the exponential decay function systematically underestimates similarity relations for stimuli relatively close together in the psychological space, and systematically overestimates similarity relations for stimuli relatively far apart in the psychological space, regardless of the distance metric that is assumed.

The better fit of the Gaussian similarity function as compared with the exponential is consistent with previous work by Nosofsky (1984a, 1985b), suggesting that the Gaussian may be superior in situations in which asymptotic performance data are collected, whereas the exponential provides a better description when nonasymptotic learning data are collected. Shepard (in press) has proposed a similar view.

The support for the Euclidean metric contrasts with almost all previous conclusions regarding the appropriate r-metric for describing psychological distance relations among separable-dimension stimuli. Possible explanations for the discrepancies between the present findings and previous ones are considered in the General Discussion section.

\section{Unconstrained MDS-Choice Model}

Having obtained evidence favoring a Gaussian similarity function and a Euclidean distance metric, the next step in the analysis was to fit the unconstrained MDS-choice 
- 1-Dimensional 1-Link Pairs

- 1-Dimensional 2-Link Pairs
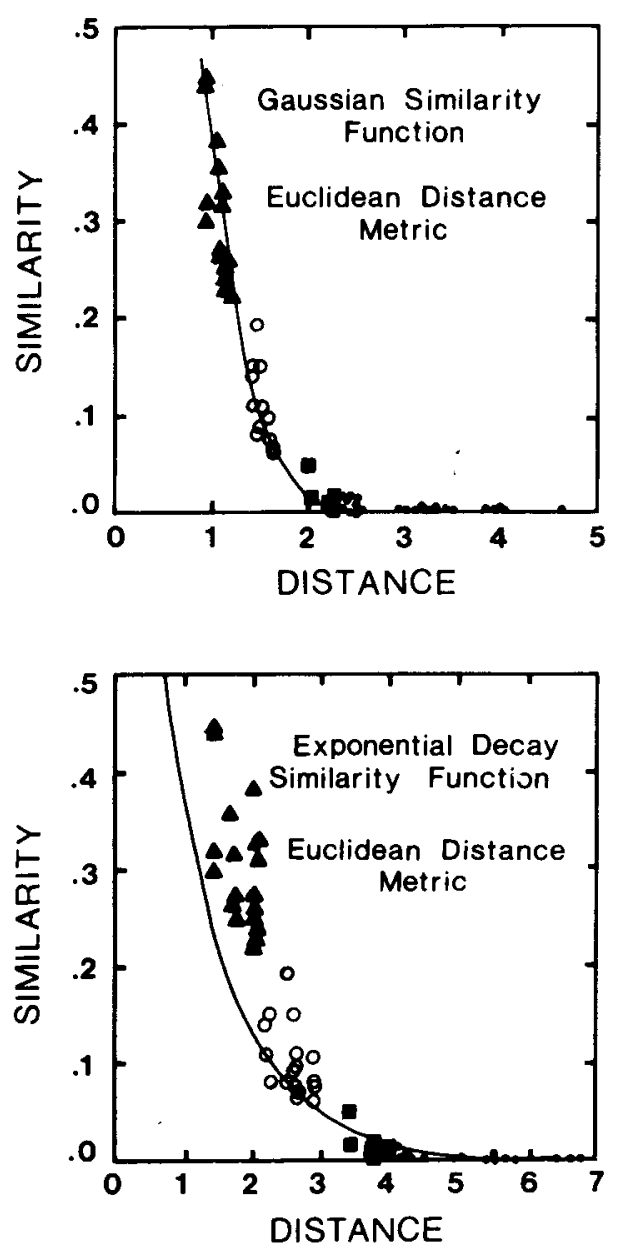

- 2-Dimensional 2-Link Pairs

- Others
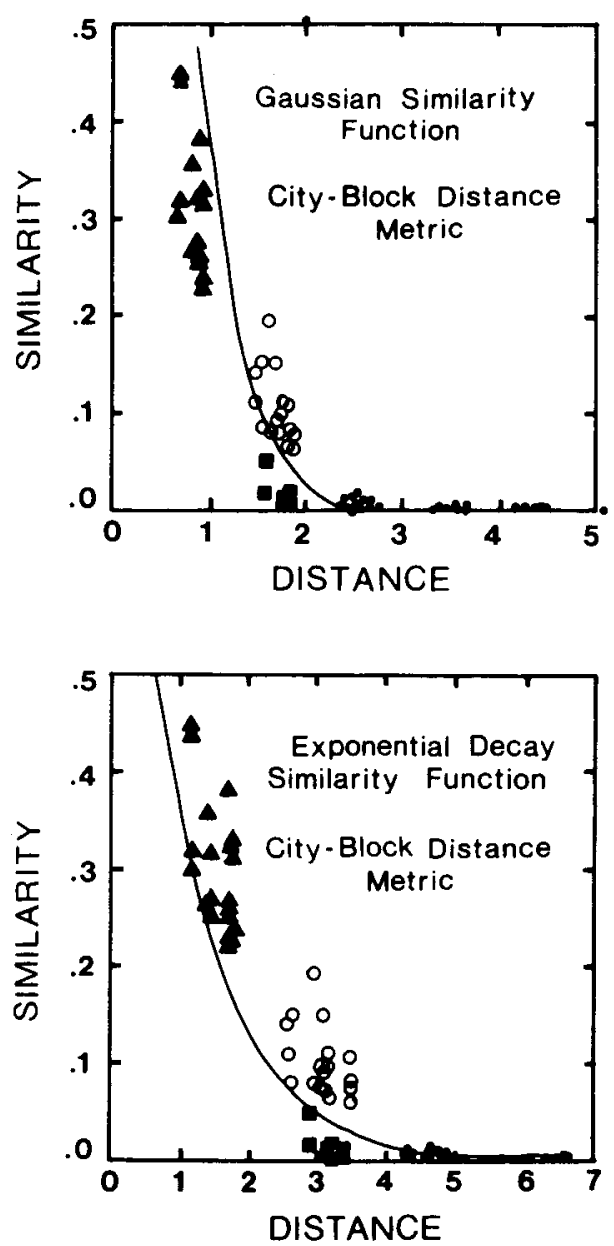

Figure 6. Graphical comparison of the alternative similarity functions and distance metrics on their ability to account for the similarity structure inherent in Subject 1's identification confusion data.

model to the identification data (i.e., all 32 coordinate parameters were free to vary). The bias parameters in Equation 1 were also allowed to vary freely. The predicted confusion frequencies are shown rounded to the nearest integer in Table 1, and the overall fit of the unconstrained Gaussian-Euclidean MDS-choice model is shown in the scatterplot in Figure 4 (bottom panels). The model accounts for $99.0 \%$ of the variance in Subject 1's data and for $97.3 \%$ of the variance in Subject 2's data. Impressively, the fit of the unconstrained MDS-choice model is not significantly worse than that of the full choice model for either Subject $1\left[\chi^{2}(90)=61.4, p>.90\right]$ or Subject $2\left[\chi^{2}(90)=93.8, p>.30\right]$. This result provides support for the multidimensional scaling approach to modeling similarity relationships among separabledimension stimuli.

The best-fitting parameters are reported in Table 3, and the coordinate parameters plotted graphically in Figure 7.
(The coordinates were rotated so that the psychological dimensions corresponded to the physical dimensions of size and angle.) The grid-like regularity evident in these plots reflects nicely the physical structure of the stimulus set, particularly the plot for Subject 1 .

\section{Constrained MDS-Choice Model}

Although the analyses using the constrained MDSchoice model (Figure 5) were considered preliminary ones, it is of interest to compare the performance of this model with that of the unconstrained MDS-choice model and the full choice model. To make appropriate comparisons, the bias parameters in Equation 1 were now allowed to vary freely. (In the previous analyses, summarized in Figure 5, the bias parameters were held fixed at those values that were maximum-likelihood estimates for the full choice model.) Thus, the constrained MDS-choice model uses 6 freely varying coordinate parameters and 
Table 3

Best-Fitting Unconst rained Gaussian-Euclidean MDS-Choice Model Parameters

\begin{tabular}{rrrrrrr}
\hline & \multicolumn{3}{c}{ Subject 1 } & \multicolumn{3}{c}{ Subject 2 } \\
\cline { 2 - 4 } \cline { 6 - 7 } & \multicolumn{1}{c}{$\mathrm{x}_{\mathrm{i} 1}$} & \multicolumn{1}{c}{$\mathrm{x}_{\mathrm{i} 2}$} & \multicolumn{1}{c}{$\mathrm{b}_{\mathrm{i}}$} & \multicolumn{1}{c}{$\mathrm{x}_{\mathrm{i} 1}$} & \multicolumn{1}{c}{$\mathrm{x}_{\mathrm{i} 2}$} & \multicolumn{1}{c}{$\mathrm{b}_{\mathrm{i}}$} \\
\hline 1 & -1.813 & -1.693 & .186 & -1.307 & -1.433 & 1.237 \\
2 & -0.594 & -1.669 & .323 & -0.430 & -1.250 & .549 \\
3 & 0.502 & -1.655 & .512 & 0.491 & -1.349 & .436 \\
4 & 1.566 & -1.606 & .765 & 1.216 & -1.134 & .432 \\
5 & -1.658 & -0.601 & .477 & -1.392 & -0.497 & .927 \\
6 & -0.479 & -0.615 & .404 & -0.382 & -0.441 & .646 \\
7 & 0.557 & -0.647 & .780 & 0.565 & -0.396 & .495 \\
8 & 1.409 & -0.476 & 1.064 & 1.409 & -0.275 & .764 \\
9 & -1.607 & 0.519 & .717 & -1.413 & 0.320 & .651 \\
10 & -0.435 & 0.551 & .583 & -0.349 & 0.268 & .709 \\
11 & 0.582 & 0.531 & .788 & 0.711 & 0.260 & .538 \\
12 & 1.451 & 0.622 & 1.140 & 1.401 & 0.474 & .669 \\
13 & -1.735 & 1.610 & .494 & -1.301 & 1.219 & .342 \\
14 & -0.514 & 1.711 & .494 & -0.232 & 1.135 & .500 \\
15 & 0.594 & 1.705 & .660 & 0.820 & 1.118 & .566 \\
16 & 1.632 & 1.701 & .613 & 1.543 & 1.438 & .537 \\
\hline
\end{tabular}

Note $-x_{\mathrm{ij}}=$ value of Stimulus $i$ on Dimension $j . b_{\mathrm{i}}=$ bias for Response $i$.

15 freely varying response bias parameters. Once again, we assume a Gaussian similarity function and a Euclidean distance metric. The best-fitting parameters are reported in Table 4. For Subject 1, the fit of the constrained MDS-choice model is not significantly worse than that of either the unconstrained MDS-choice model $\left[\chi^{2}(24)=34.6, p>.05\right]$ or the full choice model $\left[\chi^{2}(114)=96.0, p>.80\right]$. Note that only 21 free parameters were estimated to account for $98.5 \%$ of the variance in the 256-cell confusion matrix. The results for Subject 2 are quite different, however, with the fit of the constrained MDS-choice model being significantly worse than that of both the unconstrained MDS-choice model $\left[\chi^{2}(24)=116.2, p<.01\right]$ and the full choice model $\left[\chi^{2}(114)=210.0, p<.01\right]$. For Subject 2 , the model accounts for only $94.9 \%$ of the variance in the confusion matrix.
The constrained MDS-choice model embodies the assumption that the mapping of physical values onto psychological values along one dimension is independent of the value taken on along the second dimension. This assumption seems plausible for stimuli varying along highly separable dimensions. It appears that although the dimensions were perceptually separable for Subject 1 , such may not have been the case for Subject 2 .

\section{On the Relationship Between the Independent- Decisions Choice Model and the Constrained MDS-Choice Model}

The constrained Gaussian-Euclidean MDS-choice model is closely related to the independent-decisions choice model discussed earlier. The reason is that the combination of a Gaussian similarity function and a Euclidean distance metric yields an interdimensional multiplicative similarity rule:

$$
\begin{aligned}
& \eta_{\mathrm{ij}}=\mathrm{e}^{-\sqrt{\left(\mathrm{x}_{\mathrm{i} 1}-\mathrm{x}_{\mathrm{j}}\right)^{2}+\left(\mathrm{x}_{\mathrm{i} 2}-\mathrm{x}_{\mathrm{j} 2}\right)^{2}}} \\
& =e^{-\left[\left(x_{i 1}-x_{j i}\right)^{2}+\left(x_{i 2}-x_{j 2}\right)^{2}\right]} \\
& =\mathrm{e}^{-\left(x_{i 1}-x_{j}\right)^{2}} \mathrm{e}^{-\left(x_{i 2}-x_{j}\right)^{2}},
\end{aligned}
$$

where $x_{i k}$ is the psychological value of stimulus $i$ on dimension $\mathrm{k}$. Expanding the notation as before, to make explicit the two-dimensional structure of the stimulus set, the similarity between dimension-pairs $S_{\mathrm{iu}}$ and $S_{\mathrm{jv}}$ is given by

$$
\eta_{\mathrm{iu}, \mathrm{jv}}=\mathrm{e}^{-\left(\mathrm{x}_{\mathrm{iul}}-\mathrm{x}_{\mathrm{jv} \mathrm{l}}\right)^{2}} \mathrm{e}^{-\left(\mathrm{x}_{\mathrm{iu} 2}-\mathrm{x}_{\mathrm{jv} 2}\right)^{2}}
$$

where $x_{\text {ium }}$ is the psychological value of dimension-pair $\mathrm{S}_{\mathrm{iu}}$ on dimension $\mathrm{m}$. Assuming a constrained multidimensional space, the notation can be simplified by setting

$$
\mathbf{x}_{\text {iul }}=\mathbf{x}_{\text {ivl }}=\mathbf{x}_{\mathbf{i} .1}
$$

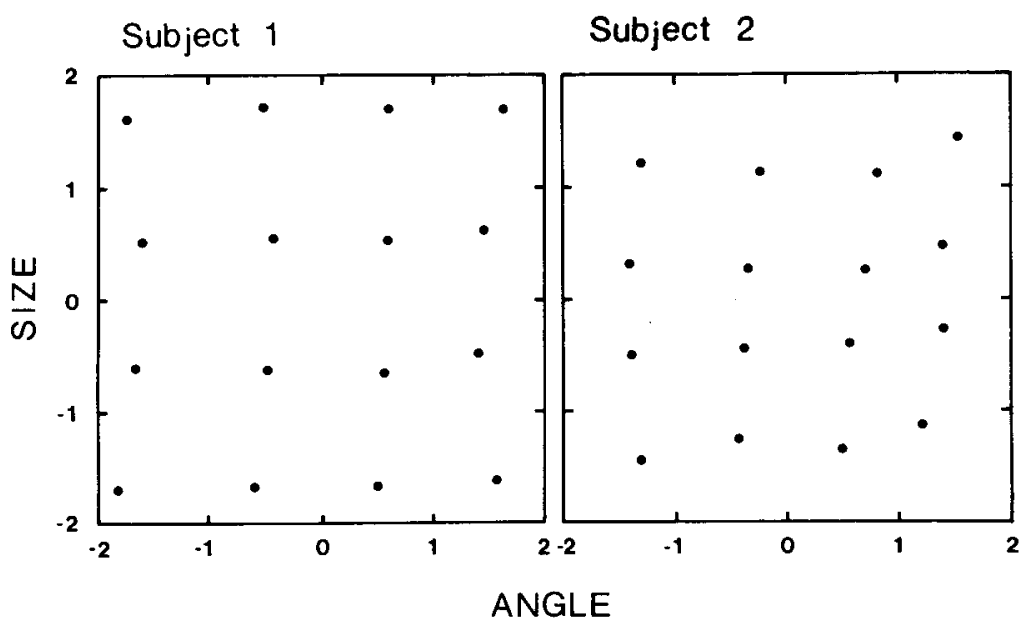

Figure 7. Multidimensional scaling solution derived by fitting the unconstrained MDS-choice model to the subjects' identification data. 


$$
\mathrm{x}_{\mathrm{iu} 2}=\mathrm{x}_{\mathrm{ju} 2}=\mathrm{x}, \mathrm{u2} .
$$

Then we have

$$
\begin{aligned}
\eta_{\mathrm{iu}, \mathrm{jv}} & =\mathrm{e}^{-\left(\mathrm{x}_{\mathrm{i} .1}-\mathrm{x}_{\mathrm{j} .1}\right)^{2} \mathrm{e}^{-\left(\mathrm{x}_{. \mathrm{u} 2}-\mathrm{x}_{. \mathrm{v} 2}\right)^{2}}} \\
& =\eta_{\mathrm{ij}}^{(1)} \eta_{\mathrm{uv}}^{(2)},
\end{aligned}
$$

where $\eta_{\mathrm{ij}}^{(1)}$ is the similarity of dimension-pairs $S_{\mathrm{iu}}$ and $S_{\mathrm{j} v}$ along dimension 1 , and so forth.

Comparing Equations 14 and $6 \mathrm{~b}$, it is evident that the similarity constraints embedded in the constrained Gaussian-Euclidean MDS-choice model are actually special cases of those embedded in the independent-decisions choice model. Restricting attention to Subject 1 , since the constrained MDS-choice model fit the data satisfactorily but the independent-decisions choice model did not, it appears that the bias constraints in Equation 5 may have been at fault. It is logically possible for a subject to perceive the components of a multidimensional stimulus in an independent manner, but for the subject's decisions regarding the value of each component not to be independent (cf. Ashby \& Townsend, in press; Garner \& Morton, 1969), and this is precisely what seems to have occurred for Subject 1. Additional analyses of Subject 1's data revealed that a major source of his decisional nonindependence was a bias against making identical component responses.

\section{SUMMARY}

The theoretical analyses are summarized as follows: (1) The full choice model provided good quantitative fits to the identification confusion data for both subjects. However, a large number of parameters needed to be estimated and little insight was provided regarding the underlying similarity structure of the stimulus set. To remedy both problems, various restricted versions of the full choice model were fitted to the identification data.

Table 4

\begin{tabular}{|c|c|c|c|c|c|c|}
\hline \multirow[b]{2}{*}{$\mathrm{j}$} & \multicolumn{3}{|c|}{ Subject 1} & \multicolumn{3}{|c|}{ Subject 2} \\
\hline & $x_{1 j}$ & $\mathbf{x}_{2 \mathrm{j}}$ & $b_{j}$ & $x_{1 j}$ & $x_{2 j}$ & $b_{j}$ \\
\hline 1 & 0.0000 & 0.0000 & .199 & 0.0000 & 0.0000 & 1.263 \\
\hline 2 & 1.1922 & 1.0727 & .335 & 0.9969 & 0.8922 & .594 \\
\hline 3 & 2.2491 & 2.2043 & .504 & 1.9781 & 1.6094 & .410 \\
\hline 4 & 3.1900 & 3.3328 & .733 & 2.7063 & 2.4844 & .437 \\
\hline 5 & & & .495 & & & .906 \\
\hline 6 & & & .406 & & & .665 \\
\hline 7 & & & .795 & & & .493 \\
\hline 8 & & & 1.089 & & & .719 \\
\hline 9 & & & .734 & & & .639 \\
\hline 10 & & & .568 & & & .708 \\
\hline 11 & & & .774 & & & .542 \\
\hline 12 & & & 1.194 & & & .679 \\
\hline 13 & & & .492 & & & .352 \\
\hline 14 & & & .476 & & & .495 \\
\hline 15 & & & .623 & & & .589 \\
\hline 16 & & & .584 & & & .508 \\
\hline
\end{tabular}

Best-Fitting Constrained Gaussian-Euclidean MDS-Choice Model Parameters

${\overline{\text { Note }}-x_{\mathrm{ij}}}=$ value of Level $j$ on Dimension $i . b_{\mathrm{j}}=$ bias for Response $j$.
(2) An "independent-decisions" model was investigated in which it was assumed that subjects identified stimuli by judging independently values along each component dimension and then combining these separate judgments into an overall response. It was shown that if the choice model characterized accurately performance along each component dimension, this independent-decisions model was a special case of the general choice model. The independent-decisions choice model fit the data significantly worse than the full choice model for both subjects, suggesting that subjects' multidimensional identification choices were not simply some independent combination of unidimensional identification choices.

(3) The multidimensional scaling approach to modeling similarity was used to reduce the number of freely varying similarity parameters in the full choice model. The MDS-choice model provided good quantitative fits to the subjects' identification data, fits that were not significantly worse than those of the full choice model.

(4) A constrained version of the MDS-choice model was also fitted to the data in which it was assumed that the psychophysical mapping of physical values onto psychological values along one dimension was independent of the values taken on along the other dimension. This constrained MDS-choice model yielded good fits for Subject 1 but not for Subject 2 . The relationship between the constrained MDS-choice model and the independentdecisions choice model was explicated, leading to a distinction between the constructs of "perceptual" independence and "decisional" independence.

(5) The multidimensional scaling analyses yielded evidence favoring a Gaussian function for relating similarity to psychological distance and a Euclidean metric for describing psychological distance relationships. The support for the Euclidean metric contrasts with virtually all previous conclusions in the perceptual classification literature regarding the appropriate $r$-metric for describing overall distance relations among separable-dimension stimuli. This result is now discussed in some depth.

\section{GENERAL DISCUSSION}

Cognitive psychologists generally assume that the behavioral output in a given task is the result of some representation-process combination (Anderson, 1976, p. 10). Various psychological processes are assumed to operate on subjects' internal representations to determine performance. Thus, tests of a particular theory of representation are made jointly with assumptions about these accompanying psychological processes.

Most previous conclusions regarding the nature of separable-dimension interactions in determining stimulus similarity have been based on studies using direct judgments of similarity. It is assumed implicitly in these studies that the judgments reflect more or less directly the underlying similarity representation. The role that decision processes may play in determining these judgments has essentially been ignored. It is important to seek some form 
of invariance in the theoretical constructs used for understanding similarity judgment data and identification confusion data. One possibility is to assume that a Euclidean distance metric provides an adequate description of the underlying similarity representation, and to interpret deviations from the Euclidean metric evidenced in similarity judgment data in terms of decision processes that operate on this representation (e.g., Nosofsky, in press).

Beyond similarity judgment tasks, another source of evidence bearing on the issue of the appropriate distance metric for separable-dimension stimuli comes from a study conducted by Shepard (1964). In addition to conducting similarity judgment tasks, Shepard (1964, Experiment 3) measured similarity among separable-dimension stimuli in terms of errors in an identification learning condition. Since his results pointed away from the Euclidean metric in the direction of the city-block metric, Shepard's study and the present one would appear to be in direct conflict. Shepard's study is now reexamined in an attempt to resolve the discrepancy.

Subjects learned to identify eight circles varying in size and angle of a radial line. An arbitrary name (one of eight letters) was assigned to each stimulus, and subjects identified the stimuli using these names. The associations between the stimuli and their assigned responses were learned by a paired-associate method of correction. Specifically, a stimulus was presented, the subject responded, the correct response was provided by the experimenter, and the next stimulus was then presented. The subjects' responses were tabulated in a stimulus-response confusion matrix that was then analyzed.

The physical structure of the stimulus set is shown in Figure 8. Preliminary scaling work indicated that dis-

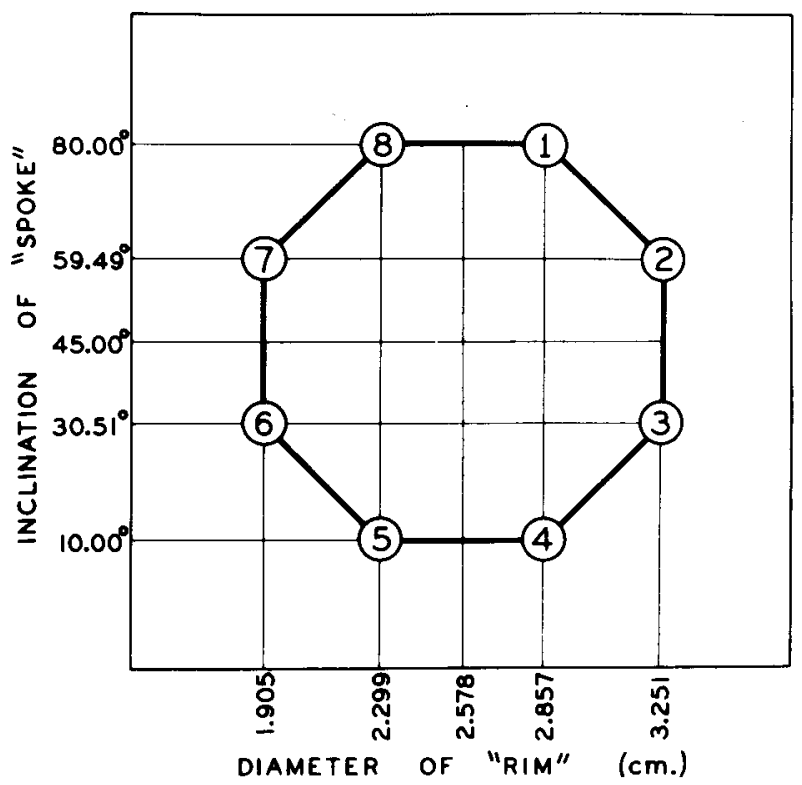

Figure 8. Physical structure of the eight stimuli used in Shepard's (1964) Experiment 3. This is Figure 6 of Shepard (1964, p. 75; reprinted by permission). criminability along each dimension was roughly equal. As a first approximation, then, the stimuli could be conceived as residing along the vertices of an equilateral octagon in Euclidean space. Since each pair of adjacent stimuli is separated by the same distance, the Euclidean metric predicts an equal number of confusions for each of the adjacent pairs (i.e., 8-1, 1-2, 2-3, etc.). By contrast, for values of $r$ less than 2 in the Minkowski r-metric formula (e.g., the city-block metric), there should be more confusions for pairs of stimuli differing along exactly one dimension (e.g., 8-1) than for pairs differing simultaneously along both dimensions (e.g., 1-2). The same qualitative predictions are also made for nonadjacent pairs such as 7-2 and 8-3, etc. These qualitative predictions are shown in the top panel of Figure 9. Even if discriminability were greater along one dimension than along the second dimension, the Euclidean and city-block metrics would still make contrasting predictions regarding the pattern of confusions, as illustrated in the bottom panel of Figure 9. As described by Shepard $(1964$, p. 74$)$, the Euclidean metric predicts that the number of confusions will go through only two cycles as one revolution is completed about the octagon, whereas the city-block metric predicts four cycles.

The results obtained by Shepard (averaged over all the subjects) are shown in Figure 10. The figure shows the frequencies with which the stimuli in the various pairs were actually confused during the identification learning condition. It is evident from inspection that the city-block metric predictions were supported and the Euclidean metric predictions contradicted. Adjacent stimuli varying along a single dimension were confused more often than those varying along both dimensions (solid jagged curve). The same pattern, although somewhat less reliable, also seems to hold for the pairs of nonadjacent stimuli (dashed jagged curve).

In what follows, I propose two factors that may have operated in Shepard's study that can account for these results, even if one maintains the assumption of a Euclidean distance metric. The first factor was actually considered by Shepard (1964, pp. 77-78) and also by Carroll and Wish (1974, pp. 425-426), but rejected as implausible. Note that the predicted pattern of confusion errors in Shepard's study rests on the assumption of a linear psychophysical mapping from physical to psychological space. It is logically possible that, in the true psychological representation, adjacent points on the octagon differing along a single dimension may be closer together in Euclidean space than may adjacent pairs differing along both dimensions. Unless some independent grounds are proposed, this explanation is clearly ad hoc. But a great deal has been learned about identification performance since 1964, and there is now information that makes the logical possibility noted above seem plausible.

In tasks of unidimensional identification for stimuli varying along a fairly wide range, a consistent and robust effect has emerged, termed by some the "resolution edge effect" (Berliner, Durlach, \& Braida, 1977; Braida \& 

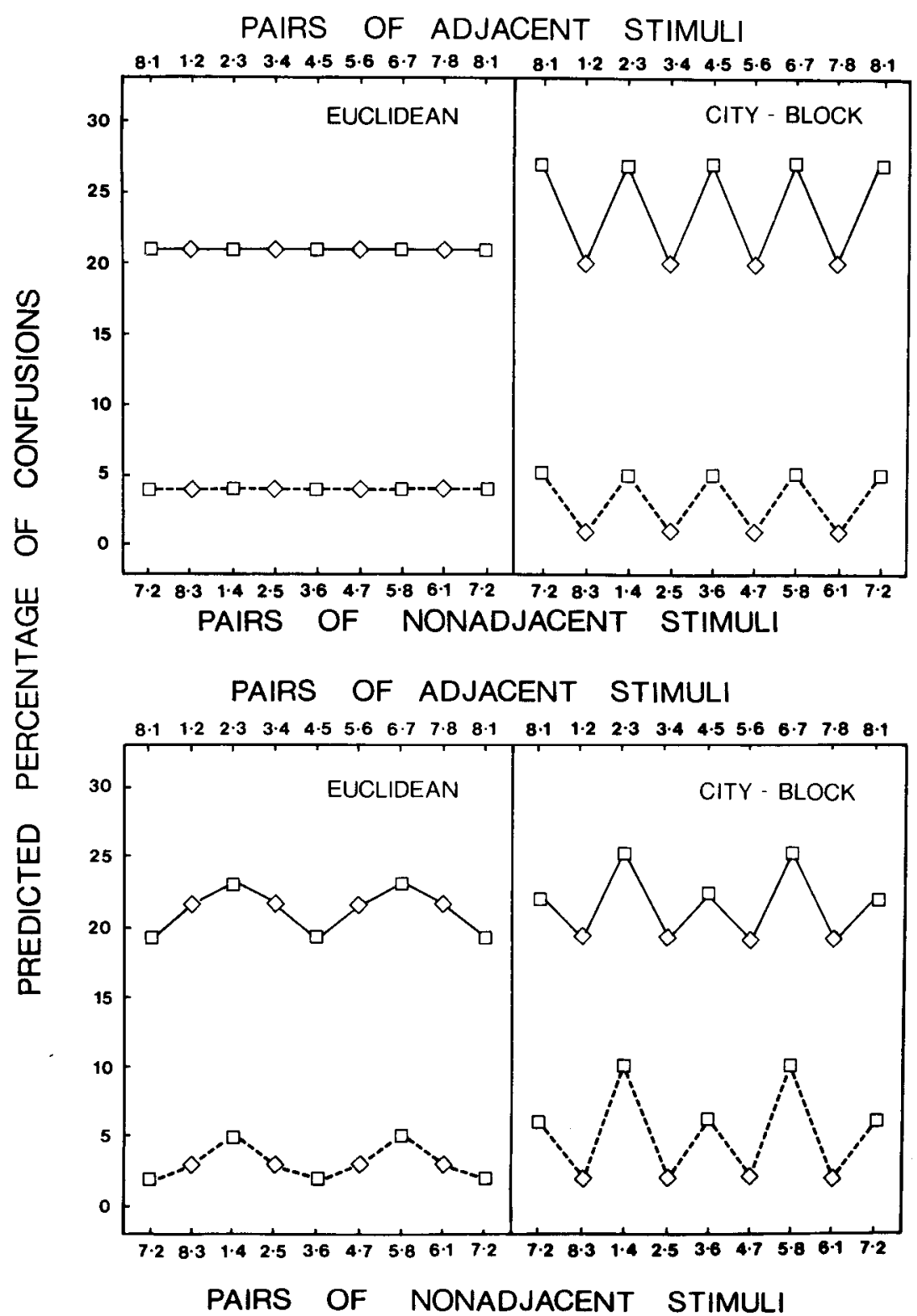

Figure 9. Predicted pattern of identification confusion errors under the Euclidean and cityblock metric assumptions. Top panel: Discriminability along the size and angle dimensions is assumed to be equal. Bottom panel: Discriminability along the size dimension is assumed to be greater than along the angle dimension. The solid curve in each panel is for the pairs of adjacent stimuli, and the dashed curve is for the pairs of nonadjacent stimuli. (Note: These predictions were generated by the MDS-choice model with the physical levels given in Figure 8 scaled by arbitrary constants.)

Durlach, 1972) and by others the "bow effect" (Luce, Nosofsky, Green, \& Smith, 1982): Stimuli at the edges of a unidimensional continuum are discriminated better than are interior stimuli. It is as if the psychological space was "stretched" at its edges. ${ }^{4}$ Various alternative theoretical mechanisms have been proposed to account for this phenomenon, including the idea that perceptual anchors are formed at the edges (Berliner \& Durlach, 1973) or that a band of selective attention may tend to locate itself at the edges (Luce, Green, \& Weber, 1976; Luce \& Nosofsky, 1984). Assuming a "resolution edge effect" for each of the dimensions in Shepard's study, one would have the situation illustrated schematically in Figure 11precisely the type of octagon (with sides alternating in length) that was posited earlier would be predicted.

Although the resolution edge effect probably played an important role in Shepard's study, this factor by itself is inadequate as a complete explanation of the results. 


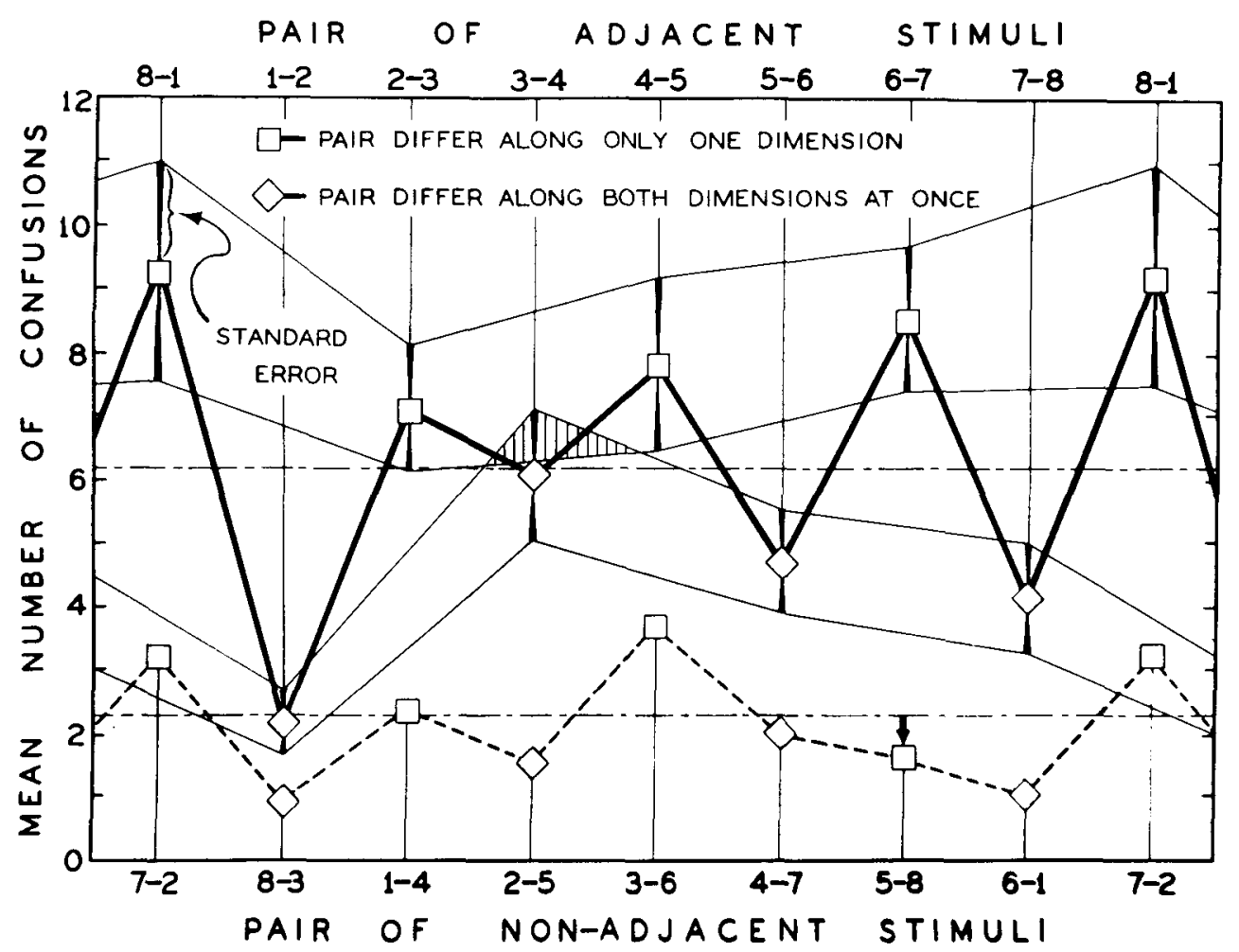

Figure 10. Observed number of confusion errors for each of the pairs of stimuli during Shepard's (1964) identification learning condition. This is Figure 7 of Shepard (1964, p. 77; reprinted by permission).

Although the pattern of errors for the adjacent pairs now seems sensible, there is still a problem for nonadjacent pairs of stimuli such as 7-2 and 8-3. According to the representation in Figure 11, stimuli 8 and 3 are closer together in Euclidean space than are stimuli 7 and 2. Yet the one-dimensional nonadjacent pairs (e.g., 7-2) seem to have been confused more often than the corresponding two-dimensional nonadjacent pairs (e.g., 8-3) (as shown

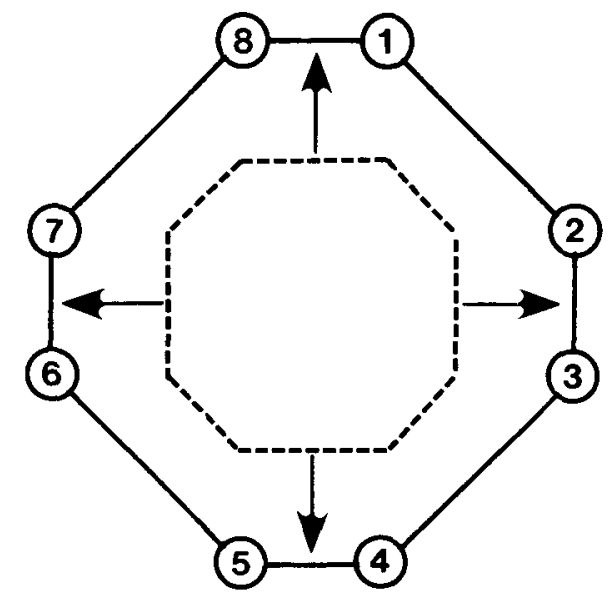

Figure 11. Schematic illustration of octagon in psychological space assuming a "resolution edge effect" for both the size and angle dimensions (see text). in Figure 10-dashed jagged curve). Furthermore, analyses of individual subject data reported by Shepard (1964, pp. 78-80) revealed certain additional effects that need to be accounted for. Correlational analyses suggested, for example, that subjects who frequently confused pairs of stimuli differing along one dimension on one side of the octagon also tended to confuse stimuli varying along that same dimension on the opposite side of the octagon (e.g., 8-1 and 4-5); but there were essentially no correlations between pairs of one-dimensional adjacent stimuli differing on opposite dimensions (e.g., 8-1 and 2-3).

Now, there are at least two important differences between the identification condition run by Shepard and the one reported here. In the present study, subjects identified the stimuli by giving two-dimensional responses, with the component responses corresponding ordinally with the physical levels of the dimensions. By contrast, Shepard's subjects used unitary labels of an arbitrary nature. Also, Shepard's was a learning study, whereas in the present study subjects were well-practiced and performing essentially at asymptote. In previous research, Nosofsky (1984a, 1985a) distinguished between the process of identification per se, in the sense of locating objects as points in a multidimensional space, and the process of learning to attach appropriate response labels to those points (see also Lockhead, 1972, p. 10). Although the importance of the response-learning component was minimized under the current experimental conditions, it must certainly 


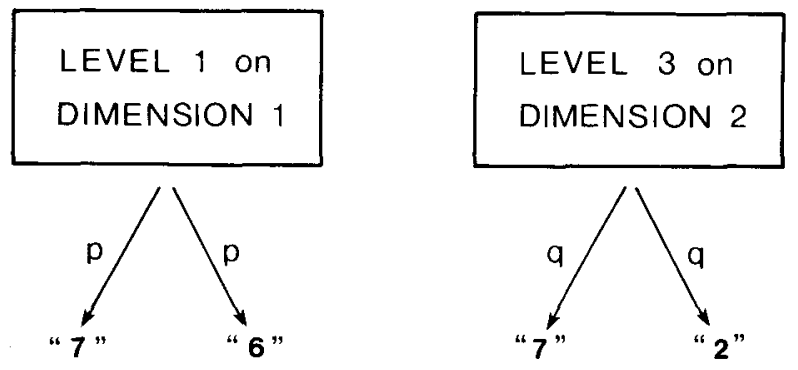

Figure 12. Schematic illustration of probabilistic S-R associations when response labels are associated with the separate components of each stimulus (see text).

have played a central role in Shepard's identification learning experiment.

Suppose that under Shepard's experimental conditions the subject is presented with stimulus 7 (see Figure 8). Since the stimuli are separable, it is plausible that the subject encodes the stimulus in terms of its component dimensions, that is, as a stimulus having level 1 on dimension 1 and level 3 on dimension 2 . Assume that by trial $n$ of the experiment, response " 7 " becomes associated with level 1 on dimension 1 with probability $p$ and with level 3 on dimension 2 with probability $q$. (The idea that responses may become associated with the separate components of the stimulus seems plausible given the literature on component selection in paired-associate learning, e.g., Underwood, Ham, \& Ekstrand, 1962.) Of course, it should also be the case that response " 6 " becomes associated with level 1 on dimension 1 with probability $p$, and that response " 2 "' becomes associated with level 3 on dimension 2 with probability q (see Figure 8 ). So we would have the situation illustrated schematically in Figure 12

Now, if all the component S-R associations shown in Figure 12 have been established, the subject has enough information available to make response " 7 " ' correctly. But if response " 7 " has not yet become associated with level 1 on dimension 1 , the subject would be forced to guess among responses " 7 ," " 6 ," and " 2 ." Note that this response-learning model predicts increased probabilities of confusion among stimuli that have identical values on component dimensions. I suggest, then, that it is not that stimuli 7 and 2 are more similar than stimuli 8 and 3 in terms of distance in psychological space. Rather, the locus of the increased confusion probability may be in the response-learning component of the identification process. The type of response-learning process outlined above might also be able to account for the results of the correlational analyses reported by Shepard, although this remains a question for future investigation.

\section{CONCLUSIONS}

The conclusions to be drawn from the present research should not be overstated. A primary purpose of this research was to study the nature of separable-dimension interactions in determining overall similarity. The dominant approach to studying this issue has been to collect direct judgments of similarity. I expressed concern with the meaningfulness of defining similarity in terms of these judgments and adopted the alternative approach of measuring similarity in terms of identification confusion errors. It should be emphasized, however, that this latter measure may also have its pitfalls. As one example, in discussing Shepard's (1964) identification learning condition, I noted the potential importance of response-learning processes in influencing the structure of identification confusion data.

Indeed, even in the present study various response processes could conceivably have contaminated the confusion matrix and obscured the underlying similarity representation. Both Shepard (in press) and an anonymous reviewer of the present article suggested that the $4 \times 4$ grid structure of the response device used in this experiment might map well onto the Euclidean assumption. Thus, any response confusions that occurred in the experiment could have been governed by the Euclidean metric, thereby accounting at least partially for the observed pattern of results.

Although this notion of Euclidean-based response confusability is a technical possibility, one can question whether it is plausible that it played a significant role in the present experiment. It is true that subjects will make errors in judging the horizontal and vertical positions of a point in space if no external criteria are available (e.g., Egeth \& Pachella, 1969). However, in the current experiment all the response buttons were simultaneously in full view and therefore served as external criteria for one another. Furthermore, the subjects had had extensive practice using the response device (over 3,200 trials prior to those that were analyzed in this report). Under these experimental conditions, it is probable that response confusability played a negligible role.

Some recent experiments that I have conducted also militate against the response-confusability hypothesis. (These experiments were not conducted with the aim of ruling out the response-confusion hypothesis but happen to bear on that hypothesis nevertheless.) Subjects identified the same type of stimuli used in the present study, namely semicircles varying in size and angle of a radial line. In one condition, 40 subjects made 200 identification responses in a single 1-h session; in a second condition, 2 subjects made 5,000 responses over a period of 2 weeks. The response device used in these experiments consisted of a single row of four labeled buttons. Subjects identified the stimuli by making two buttonpresses, first identifying the angle of the stimulus and then its size. In all the conditions, the same pattern of confusion data was observed as has already been reported herein. Of course, it is possible that even this alternative response device yielded response confusions that were governed by the Euclidean metric. Future research will need to control explicitly for possible confounds involving response confusability. 
Shepard (in press) suggested another intriguing possibility that future research will need to address. He noted that the stimuli used in this experiment were highly similar to one another, and proposed that the similarity structure of separable-dimension stimuli might depend on their overall discriminability. Although the city-block metric may describe distance relations for separable stimuli that are readily discriminated, something closer to the Euclidean metric may operate when they are difficult to discriminate. Tversky and Gati (1982, Study 11) have already provided some relevant evidence along these lines. Using similarity judgment data, they found that departures from the Euclidean metric were less severe in a lowdiscriminability condition than in a high-discriminability condition. Nevertheless, systematic departures from the Euclidean metric were always observed. Indeed, in both the high- and low-discriminability conditions, the similarity data even departed from the requirements of the cityblock metric (in a direction away from the Euclidean metric), as there were systematic violations of the triangle inequality. Still, perhaps it is only under conditions of extremely low discriminability that the effects reported in the present article will be observed.

One way to address the discriminability issue would be to collect both identification confusion data and similarity judgment data using the same set of separabledimension stimuli. If the overall discriminability of the stimuli is all that matters, then the structure of the proximity data should be the same in both conditions. On the other hand, suppose that the underlying similarity representation for separable stimuli is, in fact, Euclidean and that similarity judgment data have favored the cityblock assumption because of attention and decision processes brought to bear on that representation (see Nosofsky, in press). Then one might observe a decoupling of the two performance measures within the same experimental context. In any case, it is evident that the present research reaffirms the potential difficulties involved in generalizing conclusions across different types of stimuli and performance measures.

\section{REFERENCES}

ANDERSON, J. R. (1976). Language, memory, and thought. Hillsdale, NJ: Erlbaum.

Ashby, F. G., \& Townsend, J. T. (in press). Varieties of perceptual independence. Psychological Review.

AttNeave, F. (1950). Dimensions of similarity. American Journal of Psychology, 63, 516-556.

BerLiner, J. E., \& DurLach, N. I. (1973). A perceptual anchor model for context coding in intensity perception. Journal of the Acoustical Society of America, 54, 336A.

Berliner, J. E., Durlach, N. I., \& Braida, L. D. (1977). Intensity perception. VII: Further data on roving-level discrimination and the resolution and bias edge effects. Journal of the Acoustical Society of America, 61, 1577-1585.

BraIDA, L. D., \& DuRLACH, N. I. (1972). Intensity perception. II. Resolution in one-interval paradigms. Journal of the Acoustical Society of America, 51, 483-502.

CARroll, J. D., \& WISH, M. (1974). Multidimensional perceptual models and measurement methods. In E. C. Carterette \& M. P. Fried- man (Eds.), Handbook of perception: Psychophysical judgment and measurement (pp. 391-447). New York: Academic Press.

DunN, J. C. (1983). Spatial metrics of integral and separable dimensions. Joumal of Experimental Psychology: Human Perception \& Performance, 9, 242-257.

Egeth, H., \& Pachella, R. (1969). Multidimensional stimulus identification. Perception \& Psychophysics, 5, 341-346.

EsTES, W. K. (1982). Similarity-related channel interactions in visual processing. Journal of Experimental Psychology: Human Perception \& Performance, 8, 353-382.

GARNER, W. R. (1974). The processing of information and structure. New York: Wiley.

GARNER, W. R. (1976). Interaction of stimulus dimensions in concept and choice processes. Cognitive Psychology, 8, 98-123.

Garner, W. R., \& Felfoldy, G. L. (1970). Integrality of stimulus dimensions in various types of information processing. Cognitive Psychology, 1, 225-241.

Garner, W. R. , \& Morton, J. (1969). Perceptual independence: Definitions, models, and experimental paradigms. Psychological Bulletin, 72, 233-259.

Getty, D. J., Swets, J. B., Swets, J. A., \& Green, D. M. (1979) On the prediction of confusion matrices from similarity judgments. Perception \& Psychophysics, 26, 1-19.

HANDEL, S., \& IMAI, S. (1972). The free classification of analyzable and unanalyzable stimuli. Perception \& Psychophysics, 12, 109-116.

HOLYOAK, K. J., \& Glass, A. L. (1978). Recognition confusions among quantifiers. Journal of Verbal Learning \& Verbal Behavior, 17, 249-264.

Hyman, R., \& Well, A. (1967). Judgments of similarity and spatial models. Perception \& Psychophysics, 2, 233-248.

Hyman, R., \& Well, A. (1968). Perceptual separability and spatial models. Perception \& Psychophysics, 3, 161-165.

Kornbrot, D. (1980). Attention bands: Some implications for categorical judgment. British Journal of Mathematical \& Statistical Psychology, 33, 1-16.

KRUMHANSL, C. L. (1978). Concerning the applicability of geometric models to similarity data: The interrelationship between similarity and spatial density. Psychological Review, 85, 445-463.

Lockhead, G. R. (1972). Processing dimensional stimuli: A note. Psychological Review, 79, 410-419.

LUCE, R. D. (1959). Individual choice behavior. New York: Wiley.

LuCE, R. D. (1963). Detection and recognition. In R. D. Luce, R. R. Bush, \& E. Galanter (Eds.), Handbook of mathematical psychology (pp. 103-189). New York: Wiley.

LUCE, R. D. (1977). The choice axiom after twenty years. Journal of Mathematical Psychology, 15, 215-233.

Luce, R. D., Green, D. M., \& Weber, D. L. (1976). Attention bands in absolute identification. Perception \& Psychophysics, 20, 49-54.

LUCE, R. D., \& Nosofsky, R. M. (1984). Attention, stimulus range, and identification of loudness. In S. Kornblum \& J. Requin (Eds.), Preparatory states and processes. Hillsdale, NJ: Erlbaum.

Luce, R. D., Nosofsky, R. M., Green, D. M., \& Smith, A. F. (1982). The bow and sequential effects in absolute identification. Perception \& Psychophysics, 32, 397-408.

Monahan, J. S., \& Lockhead, G. R. (1977). Identification of integral stimuli. Journal of Experimental Psychology: General, 106, 94-110.

Nosofsky, R. M. (1983). Shifts of attention in the identification and discrimination of intensity. Perception \& Psychophysics, 33, 103-112.

Nosofsky, R. M. (1984a). Attention, similarity, and the identificationcategorization relationship. Unpublished doctoral dissertation, Harvard University.

Nosofsky, R. M. (1984b). Choice, similarity, and the context theory of classification. Journal of Experimental Psychology: Learning, Memory, \& Cognition, 10, 104-114.

NosofSKy, R. M. (1985a). Attention and learning processes in the identification and categorization of integral stimuli. Manuscript submitted for publication.

Nosofsky, R. M. (1985b). Luce's choice model and Thurstone's categorical judgment model compared: Kornbrot's data revisited. Perception \& Psychophysics, 37, 89-91. 
Nosofsky, R. M. (in press). Attention, similarity, and the identificationcategorization relationship. Journal of Experimental Psychology: General.

SHEPARD, R. N. (1957). Stimulus and response generalization: A stochastic model relating generalization to distance in psychological space. Psychometrika, 22, 325-345.

SHEPARD, R. N. (1958a). Stimulus and response generalization: Deduction of the generalization gradient from a trace model. Psychological Review, 65, 242-256.

SHEPARD, R. N. (1958b). Stimulus and response generalization: Tests of a model relating generalization to distance in psychological space. Journal of Experimental Psychology, 55, 509-523.

SHEPaRD, R. N. (1964). Attention and the metric structure of the stimulus space. Journal of Mathematical Psychology, 1, 54-87.

SHEPARD, R. N. (1984). Similarity and a law of universal generalization. Paper presented at the 25th Annual Meeting of the Psychonomic Society, San Antonio, Texas, November 9, 1984

ShePARD, R. N. (in press). Discrimination and generalization in identification and classification: Comment on Nosofsky. Journal of Experimental Psychology: General.

Sмiтн, J. E. K. (1980). Models of identification. In R. Nickerson (Ed.), Attention and performance VIII. Hillsdale, NJ: Erlbaum.

Sмiтh, J. E. K. (1982). Recognition models evaluated: A commentary on Keren and Baggen. Perception \& Psychophysics, 31, 183-189.

TORGERSON, W. S. (1958). Theory and methods of scaling. New York: Wiley.

Torgerson, W. S. (1965). Multidimensional scaling of similarity. Psychometrika, 30, 379-393.

TownSEND, J. T. (1971). Theoretical analysis of an alphatatic confusion matrix. Perception \& Psychophysics, 9, 40-50.

Townsend, J. T., \& Ashry, F. G. (1982). Experimental test of contemporary models of visual letter recognition. Journal of Experimental Psychology: Human Perception \& Performance, 8, 834-864.

Townsend, J. T., \& LANDON, D. E. (1982). An experimental and theoretical investigation of the constant-ratio rule and other models of visual letter confusion. Journal of Mathematical Psychology, 25, 119-162.

TVersky, A. (1972). Elimination by aspects: A theory of choice. Psychological Review, 79, 281-299.

TVersky, A. (1977). Features of similarity. Psychological Review, 84, 327-352.

TVERSKY, A., \& GATI, I. (1982). Similarity, separability, and the triangle inequality. Psychological Review, 89, 123-154.

UNDerwood, B. J., HAM, M., \& EKstrand, B. (1962). Cue selection in paired-associate learning. Journal of Experimental Psychology, 64, 405-409.

Wickens, T. D. (1982). Models for behavior: Stochastic processes in psychology. San Francisco: Freeman.

WIENER-EHRLICH, W. K. (1978). Dimensional and metric structures in multidimensional stimuli. Perception \& Psychophysics, 24, 399-414.

\section{NOTES}

1. One notable exception is a study conducted by Shepard (1964, Experiment 3), which I examine in some depth in the General Discussion section.

2. Formally, assuming the similarity structure in Figure 1, we would have $\Sigma \eta_{i \mathrm{k}}>\Sigma \eta_{\mathrm{jk}}$, implying that $\mathrm{P}\left(\mathrm{R}_{\mathrm{i}} \mid \mathrm{S}_{\mathrm{i}}\right)=\eta_{\mathrm{ii}} / \Sigma \eta_{\mathrm{ik}}=\eta_{\mathrm{jj}} / \Sigma \eta_{\mathrm{ik}}<$ $\eta_{\mathrm{jj}} / \Sigma \eta_{\mathrm{jk}}=\mathbf{P}\left(\mathbf{R}_{\mathrm{j}} \mid \mathbf{S}_{\mathrm{j}}\right)$. Similarly, $\mathbf{P}\left(\mathbf{R}_{\mathrm{j}} \mid \mathbf{S}_{\mathrm{i}}\right)=\eta_{\mathrm{ij}} / \Sigma \eta_{\mathrm{ik}}=\eta_{\mathrm{ji}} / \Sigma \eta_{\mathrm{ik}}<$ $\eta_{\mathrm{ji}} / \Sigma \eta_{\mathrm{jk}}=\mathbf{P}\left(\mathbf{R}_{\mathrm{i}} \mid \mathbf{S}_{\mathrm{j}}\right)$.

3. A more general experimental situation might involve the deletion of certain dimension pairs from the complete factorial set, with response pairs corresponding to these deleted stimuli disallowed by the experimenter. To apply the independent-decisions model in such a situation, some additional assumptions would need to be made to eliminate illegal response pairs. One possible assumption is that the subject undergoes a covert sequence of independent response-pair choices until a legal choice is arrived at. If this assumption were correct, then, once again, the independent-decisions choice model would be a special case of the general choice model. Note that the question of interest here is the relation between the independent-decisions choice model and the general choice model in terms of their ability to predict the data in a given identification confusion matrix. Of course, one could also add various processing assumptions to the models and attempt to distinguish them using response-time data, and so forth.

4. An anonymous reviewer argued that the resolution edge effect arises because no responses smaller than the smallest response and larger than the largest response are available to the subject. Therefore, fewer confusion responses are available at the edges of the scale, so there are fewer confusions in the data. Indeed, this factor may explain a large proportion of the variance in a confusion matrix. However, the evidence for a resolution edge effect has been obtained using Thurstone analyses (Berliner et al., 1977; Braida \& Durlach, 1972; Kornbrot, 1980) and signal detection analyses (Luce et al., 1982; Nosofsky, 1983) that take into account the restricted response choices at the edges. These analyses indicate that there is a true increase in discriminability (measured in $\mathrm{d}^{\prime}$ ) at the edges. Furthermore, Berliner et al. (1977) observed a resolution edge effect in tasks of roving-level discrimination in which subjects are required simply to make judgments of "louder" or "softer." Here, the problem of restricted response choices at the edges does not even arise. It should also be noted that Berliner et al. (1977) provided evidence that the resolution edge effect is diminished as the overall range of the stimuli decreases. Since the stimuli used in the present experiment were highly similar (i.e., varied along a narrow range), the possible absence of a resolution edge effect in the present data is consistent with Berliner et al.'s findings.

(Manuscript received July 31, 1985 revision accepted for publication November 4,1985 .) 